\title{
Exploring the Limits of Dative Boratrane Bonding: Iron as a Strong Lewis Base in Low-Valent Non-Heme Iron-Nitrosyl Complexes
}

\author{
Hai T. Dong ${ }^{1}$, Matthew J. Chalkley ${ }^{2}$, Paul H. Oyala ${ }^{2}$, Jiyong Zhao ${ }^{3}$, E. Ercan Alp ${ }^{3}$, Michael Y. \\ $\mathrm{Hu}^{3}$, Jonas C. Peters ${ }^{2,}{ }^{*}$, Nicolai Lehnert ${ }^{1}{ }^{,}$ \\ ${ }^{1}$ Department of Chemistry and Department of Biophysics, University of Michigan, Ann Arbor, \\ Michigan 48109-1055, United States \\ 2Department of Chemistry and Chemical Engineering, California Institute of Technology, \\ Pasadena, California 91125, United States \\ ${ }^{3}$ Advanced Photon Source (APS), Argonne National Laboratory (ANL), Argonne, Illinois 60439, \\ United States
}

\begin{abstract}
We previously reported the synthesis and preliminary characterization of a unique series of lowspin (ls) $\{\mathrm{FeNO}\}^{8-10}$ complexes supported by an ambiphilic trisphosphineborane ligand, $[\mathrm{Fe}(\mathrm{TPB})(\mathrm{NO})]^{+/ 0 /-}$. Herein, we use advanced spectroscopic techniques and density functional theory (DFT) calculations to extract detailed information as to how the bonding changes across the redox series. We find that, despite the highly reduced nature of these complexes, they feature an $\mathrm{NO}^{+}$ligand throughout with strong $\mathrm{Fe}-\mathrm{NO} \pi$-backbonding and essentially closed-shell electronic structures of their FeNO units. This is enabled by an Fe-B interaction that is present throughout the series. In particular, the most reduced $[\mathrm{Fe}(\mathrm{TPB})(\mathrm{NO})]^{-}$complex, an example of a ls- $\{\mathrm{FeNO}\}^{10}$ species, features a true reverse dative $\mathrm{Fe} \rightarrow \mathrm{B}$ bond where the $\mathrm{Fe}$ center acts as a strong Lewis-base. Hence, this complex is in fact electronically similar to the $1 \mathrm{~s}-\{\mathrm{FeNO}\}^{8}$ system, with two additional electrons "stored" on site in an Fe-B single bond. The outlier in this series is the 1s- $\{\mathrm{FeNO}\}\}^{9}$ complex, due to spin polarization (quantified by pulse EPR spectroscopy), which weakens the Fe$\mathrm{NO}$ bond. These data are further contextualized by comparison with a related $\mathrm{N}_{2}$ complex, $\left[\mathrm{Fe}(\mathrm{TPB})\left(\mathrm{N}_{2}\right)\right]^{-}$, which is a key intermediate in $\mathrm{Fe}(\mathrm{TPB})$-catalyzed $\mathrm{N}_{2}$ fixation. Our present study finds that the $\mathrm{Fe} \rightarrow \mathrm{B}$ interaction is key for storing the electrons needed to achieve a highly reduced state in these systems, and highlights the pitfalls associated with using geometric parameters to try to evaluate reverse dative interactions, a finding with broader implications to the study of transition metal complexes with boratrane and related ligands.
\end{abstract}

\section{Graphical Abstract}

*Corresponding Authors. lehnertn@umich.edu, jpeters@caltech.edu.

Supporting Information.

Details of the pulse EPR simulations, coordinates of optimized molecules, and Table S1 can be found in the SI.

This material is available free of charge via the Internet at http://pubs.acs.org.

The authors declare no competing financial interest. 


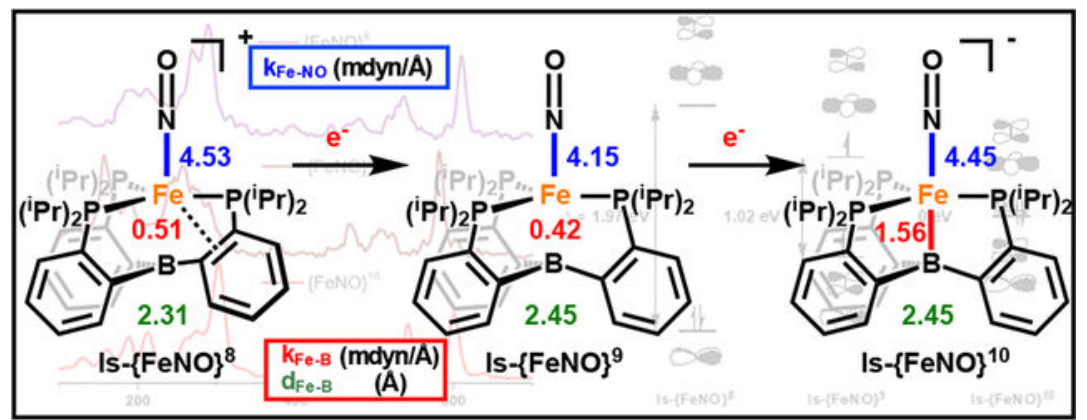

We use advanced spectroscopic methods and DFT calculations to interrogate the electronic structure of our unique redox series of $[\mathrm{Fe}(\mathrm{TPB})(\mathrm{NO})]^{+/ 0 /-}$ complexes. We find that the $\mathrm{Fe} \rightarrow \mathrm{B}$ interaction is key for storing the electrons needed to achieve a highly reduced state in these systems. Comparison is further made to the related $\mathrm{N}_{2}$ complex, $\left[\mathrm{Fe}(\mathrm{TPB})\left(\mathrm{N}_{2}\right)\right]^{-}$, which is a key intermediate in $\mathrm{Fe}(\mathrm{TPB})$-catalyzed $\mathrm{N}_{2}$ fixation.

\section{Introduction}

Heme and non-heme iron-nitrosyl units are highly prevalent in biology, and (bio)inorganic chemists have pondered their electronic structures and reactivity patterns for decades to better understand these systems. In particular, heme-nitrosyls are relevant in NO sensing, transport and as intermediates in nitrogen-cycle enzymes, ${ }^{1-12}$ whereas non-heme iron centers are particularly relevant in bacterial NO reductases (NORs). ${ }^{13-16}$ Transition metal nitrosyl (M-NO) complexes represent some of the earliest recognized examples of redox non-innocence, leading to the development of the Enemark-Feltham notation, $\{\mathrm{MNO}\}^{n}$, which classifies a M-NO complex by its total number of valence electrons $n(=$ metal(d) + $\mathrm{NO}\left(\pi^{*}\right)$ electrons $) .{ }^{17}$ In this regard, NO can coordinate to metals in three different oxidation states $\left(\mathrm{NO}^{+/ 0 /-}\right)$. In the case of non-heme iron enzymes, for example, binding of $\bullet \mathrm{NO}$ to the $\mathrm{Fe}(\mathrm{II})$ form generates high-spin (hs) $\{\mathrm{FeNO}\}^{7}$ adducts, which, in general, have $\mathrm{Fe}^{\mathrm{III}}-\mathrm{NO}^{-}$ type electronic structures. ${ }^{18-20}$ Due to their highly covalent Fe-NO bonds, these complexes are usually stable and unreactive (with NORs being potential exceptions), but capable of undergoing reduction at mild potentials to form very reactive hs- $\{\mathrm{FeNO}\}^{8}$ complexes..$^{21-24}$ The latter species have been shown to undergo a number of different reactions, including $\mathrm{N}$ $\mathrm{N}$ coupling to form $\mathrm{N}_{2} \mathrm{O},{ }^{25-27}$ disproportionation to form dinitrosyl iron complexes (DNICs), ${ }^{28}$ and protonation to generate HNO. ${ }^{29}$ Recent findings by Balkus and coworkers show that non-heme iron enzymes are also involved in biosynthetic pathways of natural products containing the $\mathrm{N}$-nitroso group, with a hs- $\{\mathrm{FeNO}\}^{6}$ intermediate potentially involved in this reaction. ${ }^{30}$ Understanding how the electron distribution effects the reactivity and stability of Fe-NO complexes is of critical importance to develop a better understanding of their many roles both in signaling and energy-transducing reactions in biology.

Given the non-innocent nature of the $\bullet \mathrm{NO}$ ligand, redox series of non-heme Fe-NO complexes with the same ligand scaffold are of particular value for developing a better understanding of the electronic structure of the M-NO unit. This is highlighted by two wellstudied examples of $\{\mathrm{FeNO}\}^{6-8}$ complexes, a cyclam-supported low-spin (ls) system from Wieghardt and coworkers ${ }^{31}$ and $\mathrm{TMG}_{3}$ tren-supported hs system from Lehnert and 
coworkers ${ }^{24}$ which revealed significantly different electronic structures. The former is bestdescribed as $\mathrm{Fe}^{\mathrm{II}}$ coordinated to $\mathrm{NO}^{+/ 0 /-}$ in turn; whereas the latter is best described as $\mathrm{Fe}^{\mathrm{IV} / \mathrm{III} / \mathrm{II}}$ antiferromagnetically coupled to ${ }^{3} \mathrm{NO}^{-}$. However, going beyond the $\{\mathrm{FeNO}\}^{8}$ oxidation state has been a challenge in both hs and ls Fe-NO complexes, because it means that either $\mathrm{Fe}(\mathrm{I})$ or $\mathrm{NO}^{2-}$ species must be stabilized. More recently, two redox series that expand the accessible Enemark-Feltham states for Fe have been reported. The first, from Peters and coworkers, consisted of a 1s- $\{\mathrm{FeNO}\}^{8-10}$ redox series supported by a trisphosphineborane ligand (TPB = tris[2-(di-iso-propylphosphino)phenyl]borane); see Scheme 1). ${ }^{32}$ These compounds, denoted $[\mathrm{Fe}(\mathrm{TPB})(\mathrm{NO})]^{+/ 0 /-}$, are surprisingly stable and could be characterized by X-ray crystallography. The only other series of mononitrosyl complexes that reaches beyond the $\{\mathrm{FeNO}\}^{8}$ state, $\left[\mathrm{Fe}\left(\mathrm{TIMEN}^{\mathrm{Mes}}\right)(\mathrm{NO})\right]^{2 /+/+/ 0 /-}$, was recently reported by Meyer and coworkers. ${ }^{23}$ Therein, the hs- $\{\mathrm{FeNO}\}^{7-9}$ redox states were isolable while the putative $\{\mathrm{FeNO}\}^{10}$ immediately undergoes NO insertion into the triscarbene supporting ligand.

In this study, we present a full spectroscopic and electronic structure analysis of the $[\mathrm{Fe}(\mathrm{TPB})(\mathrm{NO})]^{+/ 0 /-}$ series. In these complexes, a second redox-active unit, namely a borane, is positioned in close proximity to the metal by the ligand architecture. Ambiphilic ligands that utilize Lewis base donors both to coordinate a metal center and position a Lewis acid (LA) in its proximity have become increasingly popular in the past two decades. ${ }^{33-35}$ However, given the constraints imposed by the ligand scaffolds used, evaluating the degree M-LA bonding is often challenging.

Herein, we demonstrate the utility of force constants derived from quantum-chemistry centered normal coordinate analysis (QCC-NCA) of nuclear resonance vibrational spectroscopy (NRVS) data in deconvoluting the electronic structure and bonding at Fe in a highly covalent ligand sphere comprised of nitrosyl, boratrane, and phosphine ligands. We find that, despite their low formal $\mathrm{Fe}$ redox states, an $\mathrm{NO}^{+}$redox state with strong $\mathrm{Fe}-\mathrm{NO} \pi$ bonds is maintained throughout the redox series. This is made possible because of the high degree of structural and electronic flexibility in the TPB ligand, demonstrated via the breaking of an $\eta^{4}$-BCCP donor interaction present in the most oxidized complex, and formation of a reverse dative $\mathrm{Fe} \rightarrow \mathrm{B}$ bond in the most reduced complex. Similarly, a reverse dative $\mathrm{Fe} \rightarrow \mathrm{B}$ bond has also been identified in the structurally related $\left[\mathrm{Fe}(\mathrm{TPB})\left(\mathrm{N}_{2}\right)\right]^{-}$ complex by NRVS, underscoring the relevance of this interaction in promoting small molecule functionalization (i.e., $\mathrm{N}_{2}$ fixation). ${ }^{36}$ These conclusions are corroborated by continuous wave and pulse electron paramagnetic resonance spectroscopy (EPR) and density functional theory (DFT) calculations.

\section{Experimental Section}

All complexes including ${ }^{57} \mathrm{Fe}$ complexes were prepared as previously reported and obtained as pure compounds, as determined by Mössbauer and IR spectroscopy. ${ }^{32}$ Efforts to label the complexes with ${ }^{15} \mathrm{NO}$ were largely unsuccessful. However, trace amounts of the 1s- $\{\mathrm{FeNO}\}^{9}$ complex $\left[\mathrm{Fe}(\mathrm{TPB})\left({ }^{15} \mathrm{NO}\right)\right]$, sufficient for pulse EPR measurements, could be obtained via reaction of $\left[\mathrm{Fe}(\mathrm{TPB})\left(\mathrm{N}_{2}\right)\right]$ with $[\mathrm{TBA}]\left[{ }^{15} \mathrm{NO}_{2}\right]$ followed by extraction by pentane and filtration through celite. 


\section{NRVS measurements.}

Nuclear resonance vibrational spectroscopy (NRVS) data were obtained as described previously $^{3}$ at beamline 3-ID at the Advanced Photon Source (APS) at Argonne National Laboratory. Samples were loaded in copper sample holders with lucite lids. During data collection, samples were maintained at cryogenic temperatures using a liquid helium-cooled cryostat. Spectra of solid samples were recorded from 0 to $+90 \mathrm{meV}$ in $0.25 \mathrm{meV}$ steps. Multiple scans were taken, normalized to the intensity of the incident beam, and added together to achieve adequate signal to noise ratios; the final spectra represent averages between 6 and 10 scans. The program Phoenix ${ }^{4}$ was used to convert the raw NRVS data to the vibrational density of states (VDOS).

\section{Pulse EPR measurements for the Is- $\{\mathrm{FeNO}\}^{9}$ complex.}

All pulse X-band $(\nu \approx 9.7 \mathrm{GHz})$ EPR and electron nuclear double resonance (ENDOR) experiments were performed using a Bruker (Billerica, MA) ELEXSYS E580 pulse EPR spectrometer equipped with a Bruker MD-4 resonator. Temperature control for experiments at $7 \mathrm{~K}$ was achieved using an ER 4118HV-CF5-L Flexline Cryogen-Free VT cryostat manufactured by ColdEdge (Allentown, PA), while ENDOR experiments at $5 \mathrm{~K}$ were performed using an Oxford Instruments CF935 helium flow cryostat. An Oxford Instruments Mercury ITC was used for temperature regulation with both cryostats.

X-band Electron spin-echo detected field swept spectra (ESE-EPR) were acquired using the 2-pulse Hahn echo sequence $\left(\frac{\pi}{2}-\tau-\pi-\tau-e c h o\right)$, while the magnetic field was varied. The "CW-EPR like" $1^{\text {st }}$ derivative spectrum was generated by use of the pseudomodulation function in EasySpin, an EPR simulation toolbox for use with Matlab. ${ }^{37,38}$

Pulse X-band ENDOR was acquired using the Davies pulse sequence $\left(\pi-T_{R F}-\pi_{R F}-T_{R F}\right.$ $\pi / 2-\tau-\pi$-echo), where $T_{R F}$ is the delay between mw pulses and RF pulses, $\pi_{R F}$ is the length of the RF pulse and the RF frequency is randomly sampled during each pulse sequence.

X-band Hyperfine sublevel correlation (HYSCORE) spectra were acquired using the 4-pulse sequence $\left(\pi / 2-\tau-\pi / 2-t_{1}-\pi-t_{2}-\pi / 2-\right.$ echo), where $\tau$ is a fixed delay, while $t_{1}$ and $t_{2}$ are independently incremented by $\Delta t_{1}$ and $\Delta t_{2}$, respectively. The time domain data was baseline-corrected (third-order polynomial) to eliminate the exponential decay in the echo intensity, apodized with a Hamming window function, zero-filled to eight-fold points, and fast Fourier-transformed to yield the 2-dimensional frequency domain. The intensity of this FT data was plotted as a series of contours on a logarithmic scale, in colors ranging from blue to red in increasing intensity.

EPR Simulations.-Simulations of all EPR data were achieved using the EasySpin simulation toolbox (release 5.2.28) with Matlab 2019a ${ }^{37}$ For more details of these simulations, we refer readers to the SI. 


\section{DFT Calculations using Gaussian 09 and Normal Coordinate Analysis.}

Geometry optimization of the 1s- $\{\mathrm{FeNO}\}^{8-10}$ complexes was carried out using the BP86 and B3LYP functionals with the TZVP basis set, using both closed shell and broken symmetry wavefunctions (see text). All calculations were performed using the program Gaussian 09. ${ }^{39}$ Subsequent frequency calculations on the optimized structures show no imaginary frequencies, indicating that true energy minima were obtained. The DFT-calculated force constants in Cartesian coordinates were extracted from the Gaussian output files and transformed into internal coordinates using a modified version of the program Redong. Modified normal coordinate analysis (NCA) programs based on QCPE 576 were used for the subsequent fitting of the experimental NRVS data. The fitting was performed by adjusting a minimal set of force constants (in the spirit of the QCC-NCA approach) ${ }^{40}$ to reproduce the vibrations of the $\mathrm{Fe}-\mathrm{N}-\mathrm{O}$ units in the $\mathrm{ls}-\{\mathrm{FeNO}\}^{8-10}$ series of complexes (see text).

\section{DFT Calculations using ORCA 4.0.}

The Gaussian-optimized structures of the 1s- $\{\mathrm{FeNO}\}^{8-10}$ complexes were used for following single-point calculations (BP86/TZVP) with ORCA 4.0 to predict Mössbauer and EPR parameters, and to further analyze the electronic structures of the complexes. This includes the use of unrestricted corresponding orbitals (UCOs) for the 1s- $\{\mathrm{FeNO}\}^{9}$ complex. $^{41}$

\section{Results and Analysis}

\subsection{Nuclear Resonance Vibrational Spectroscopy (NRVS) for the Is-\{FeNO\}8-10 Series}

The Fe-NO bonding in the 1s- $\{\mathrm{FeNO}\}^{8-10}$ series is evaluated and analyzed herein based on NRVS measurements (see Figure 1). NRVS is a vibrational technique that selectively detects vibrations that involve the ${ }^{57} \mathrm{Fe}$ center, making it well-suited for the identification of $\mathrm{Fe}$ ligand stretching and bending modes. The experimental NRVS data of the $1 \mathrm{~s}-\{\mathrm{FeNO}\}^{8}$ complex reveal an intense band at $610 \mathrm{~cm}^{-1}$ and weaker signals at 537 and $540 \mathrm{~cm}^{-1}$. The feature at $610 \mathrm{~cm}^{-1}$ is assigned to the FeNO stretch (see below), whereas those at 537 and $540 \mathrm{~cm}^{-1}$ are in the correct range for Fe-N-O bending modes. With an Fe-NO stretch of 610 $\mathrm{cm}^{-1}$, this complex has one of the strongest transition metal-NO bonds observed to this date and the strongest for an iron compound, ${ }^{42}$ surpassing even $1 \mathrm{~s}-\{\mathrm{FeNO}\}^{6}$ complexes in hemes (with typical Fe-NO stretching frequencies around $\left.590 \mathrm{~cm}^{-1}\right) .{ }^{43,44}$ In IR spectroscopy, the $\mathrm{N}-\mathrm{O}$ stretch of this complex is observed at $1745 \mathrm{~cm}^{-1}$. The NRVS data of the $1 \mathrm{~s}-\{\mathrm{FeNO}\}^{10}$ complex are remarkably similar to those of the $1 \mathrm{~s}-\{\mathrm{FeNO}\}^{8}$ species described above. In particular, its Fe-NO stretch is observed as the most intense signal at $602 \mathrm{~cm}^{-1}$, with the weaker features at 525 and $543 \mathrm{~cm}^{-1}$ again associated with Fe-N-O bending modes (see Figure 1). The N-O bond of this complex is the weakest (and most activated) in the series, with an $\mathrm{N}-\mathrm{O}$ stretching frequency of $1568 \mathrm{~cm}^{-1}$ as determined by IR spectroscopy.

The intense, high-energy NRVS feature of the ls- $\{\mathrm{FeNO}\}^{9}$ species, observed at $583 \mathrm{~cm}^{-1}$, is again assigned to the Fe-NO stretch. This mode is significantly shifted compared to $610 \mathrm{~cm}$ $-1\left(\Delta \nu=-27 \mathrm{~cm}^{-1}\right)$ and $602 \mathrm{~cm}^{-1}\left(\Delta \nu=-19 \mathrm{~cm}^{-1}\right)$ in the other two complexes, respectively, which, as we will show below, is due to spin polarization. The Fe-N-O bending 
modes are similarly shifted as well (506 and $522 \mathrm{~cm}^{-1}$, see Figure 1). The N-O stretch of this complex is located at $1667 \mathrm{~cm}^{-1}$.

In summary, comparison of the Fe-NO and $\mathrm{N}-\mathrm{O}$ stretching frequencies along the ls$\{\mathrm{FeNO}\}^{8-10}$ series does not reveal a consistent trend. In a simple $\pi$-backbonding model (between the $\mathrm{Fe}-\mathrm{d}$ and $\mathrm{NO}\left(\pi^{*}\right)$ orbitals), we would anticipate that concomitant with the observed stepwise weakening of the N-O bond along the 1s- $\{\mathrm{FeNO}\}^{8-10}$ series there would be a stepwise strengthening of the FeNO bond. Instead, for the 1s- $\{\mathrm{FeNO}\}^{8 / 9}$ pair, both the Fe-NO and N-O stretching frequencies (and bond strengths) decrease in the 1s- $\{\mathrm{FeNO}\}^{9}$ compound. This trend is then reversed in the $1 \mathrm{~s}-\{\mathrm{FeNO}\}^{9 / 10}$ pair (now showing a pattern that would be in line with an increase in $\pi$-backbonding upon reduction), creating a discontinuity in the observed behavior. Thus, it is clear that a more detailed analysis, one that considers all available experimental data supported by electronic structure calculations, is necessary.

DFT Calibration for the Is-\{FeNO $\}^{8-10}$ Series.-In our previous report, the 1s$\{\mathrm{FeNO}\}^{8}$ and ls- $\{\mathrm{FeNO}\}^{10}$ complexes were described as closed shell systems, on the basis of their diamagnetic ground states (from multinuclear nuclear magnetic resonance (NMR) spectroscopy). Alternatively, diamagnetic ground states could also arise from strong antiferromagnetic coupling between a hs iron center and a triplet $\mathrm{NO}^{-}$ligand, which is often observed for non-heme Fe-NO complexes. ${ }^{24}$ Furthermore, a recent interrogation of a related redox series, $\left[\mathrm{Fe}(\mathrm{TPB})\left(\mathrm{NNMe}_{2}\right)\right]^{+/ 0 /-}$, by experiment and theory revealed antiferromagnetic coupling between the Fe center and a hydrazyl radical anion, $\left[\mathrm{NNMe}_{2}\right]^{--}$in some redox states. ${ }^{45}$ Therefore, we decided to re-evaluate whether the ground states of the [Fe(TPB) $(\mathrm{NO})]^{+/ 0 /-}$ complexes are best described by closed shell (CS) or broken-symmetry (BS) wave functions. As in previous work, we applied both the gradient-corrected functional BP86 and the hybrid functional B3LYP in combination now with the TZVP basis set for these calculations. ${ }^{46-50}$ While BP86 has previously been shown to be a reliable functional in predicting geometric structures and spectroscopic properties of iron-nitrosyl complexes, B3LYP tends to underestimate the covalency of the Fe-N-O moiety. ${ }^{51,52}$ However, hybrid functionals like B3LYP with a higher percentage of Hartree-Fock exchange often allow for the geometry optimization of BS states in strongly spin-coupled systems, which is difficult with gradient-corrected functionals like BP86.

To our surprise, the structural features derived from X-ray crystallography were wellreproduced by both the CS and BS state in B3LYP calculations on the $1 \mathrm{~s}-\{\mathrm{FeNO}\}^{8}$ complex (see Table S1). For example, the N-O bond length only deviates by $0.01 \AA$ for both states (1.16/1.17/1.17 $\AA$ for exp/CS/BS). Similarly, the Fe-NO bond distance shows very good agreement with the experimental data, with just $0.01-0.02 \AA$ deviation for both states (1.66/1.65/1.68 $\AA$ for exp/CS/BS). Both calculations show moderate agreement with the experimental Fe-B bond distance (2.31/2.37/2.37 $\AA$ for exp/CS/BS). Finally, the BS state shows better agreement with the experimental data for the Fe-N-O angle $\left(176 / 172 / 175^{\circ}\right.$ for exp/CS/BS). Thus, although purely structural comparisons do not distinguish between a CS or BS electronic structure for the $1 \mathrm{~s}-\{\mathrm{FeNO}\}^{8}$ complex, the accuracy of the predicted NRVS spectra is dramatically different, as shown in Figure 2. Whereas the predicted spectrum for CS shows very good agreement with experiment, the BS calculation shows large deviations from the experimental data (Fe-NO stretch: $610 / 654 / 490 \mathrm{~cm}^{-1}$ for exp/CS/BS). Interestingly, 
the BS-predicted $\mathrm{Fe}-\mathrm{NO}$ stretch at $490 \mathrm{~cm}^{-1}$ is in line with experimentally determined $\mathrm{Fe}$ NO stretching frequencies in complexes featuring ${ }^{3} \mathrm{NO}^{-}$ligands,,${ }^{24,53,54}$ suggesting that the disagreement is not an artifact of the calculation. In summary, this result shows that the CS wavefunction provides a better representation of the ground state electronic structure of the $1 \mathrm{~s}-\{\mathrm{FeNO}\}^{8}$ complex, which differs from most other (trigonal-bipyramidal) non-heme ironNO complexes. ${ }^{21-24}$

Comparing CS solutions calculated with both B3LYP and BP86, we find that the BP86 functional not only better reproduces the vibrational and structural data for the ls$\{\mathrm{FeNO}\}^{8-10}$ series, but is also able to accurately predict the isomer shift $(\delta)$ and quadrupole splitting $\left(\left|\Delta_{\text {eq }}\right|\right)$ derived from Mössbauer spectroscopy and the hyperfine parameters derived from pulse EPR spectroscopy (Table 1). Thus, we confirm that a CS, highly covalent description of the ground state in the $[\mathrm{Fe}(\mathrm{TPB})(\mathrm{NO})]^{+/ 0 /-}$ complexes is most appropriate.

The BP86-optimized structures show very good agreement with the crystal structures of all three compounds, as further demonstrated by the structural overlays in Figure 3. The 1s$\{\mathrm{FeNO}\}^{8}$ complex has a distinct distorted trigonal-bipyramidal geometry, where one of the $\mathrm{P}-\mathrm{Fe}-\mathrm{P}$ angles in the trigonal plane is expanded to $154^{\circ}$ allowing for an unusual intramolecular $\eta^{4}$-BCCP interaction. Both of these features are well reproduced in the DFT optimized structure. As the compound is reduced to the $1 \mathrm{~s}-\{\mathrm{FeNO}\}^{9}$ state, the complex becomes more symmetric (closer to an actual trigonal-bipyramidal geometry), and the unusually large P-Fe-P angle decreases from $154^{\circ}$ to $126^{\circ}$. The ls- $\{\mathrm{FeNO}\}^{10}$ complex is the most symmetric with only about $1^{\circ}$ difference between the three P-Fe-P angles.

The BP86 calculations reproduce the vibrational properties of the 1s- $\{\mathrm{FeNO}\}^{8-10}$ complexes, especially the Fe-NO and $\mathrm{N}-\mathrm{O}$ stretching frequencies, quite well with respect to experimental data (Figures S1). Importantly, the calculations capture the lack of a correlation between the change in Fe-NO and N-O stretching frequencies along the 1s- $\{\mathrm{FeNO}\}^{8-10}$ series (see Table 1). Thus, we use these calculations as the basis to further analyze the NRVS data and refine the force constants of the $\mathrm{Fe}-\mathrm{N}-\mathrm{O}$ units in the three complexes. In this way, we further address the question of whether the reduction along the ls- $\{\mathrm{FeNO}\}^{8-10}$ series is metal- or NO-based.

QCC-NCA for the Is- $\{\mathrm{FeNO}\}^{8-10}$ Series.-To obtain simulations of the NRVS data of the 1s- $\{\mathrm{FeNO}\}^{8-10}$ complexes and determine high-quality (experimental) force constants for their Fe-N-O units, a quantum-chemistry centered normal coordinate analysis (QCC-NCA) was performed. ${ }^{45,55}$ This process allows us to correct the DFT-calculated force constants, vibrational frequencies and NRVS intensities by fitting the experimental NRVS data, starting from the DFT-predicted force field. In this way, we obtain high-quality force constants for the modes of interest that afford detailed insight into the changes in $\mathrm{Fe}-\mathrm{NO}$ and $\mathrm{N}-\mathrm{O}$ bonding along the ls- $\{\mathrm{FeNO}\}^{8-10}$ series, independent of potential vibrational (mode) mixing. In the spirit of the QCC-NCA approach, ${ }^{55}$ only the small number of force constants relevant to the Fe-N-O unit are varied, while the DFT-predicted force constants of the $[\mathrm{Fe}(\mathrm{TPB})]$ frame are kept unchanged. 
For the ls- $\{\mathrm{FeNO}\}^{8}$ complex, the Fe-NO force constant was corrected from the calculated value of 4.95 to $4.53 \mathrm{mdyn} / \AA$ to fit the Fe-NO stretch at $610 \mathrm{~cm}^{-1}$ (DFT-calculated value: $638 \mathrm{~cm}^{-1}$ ). Since the Fe-N-O unit is close to linear, the Fe-N-O unit has two linear bending vibrations, which are assigned to the modes at 537 and $540 \mathrm{~cm}^{-1}$ in the NRVS data, with force constants of 0.41 and $0.57 \mathrm{mdyn} \bullet \AA$. The relatively high anisotropy of the two linear bends is consistent with the strong deviation from trigonal symmetry in the $\mathrm{FeP}_{3}$ plane. The experimental N-O force constant of $12.5 \mathrm{mdyn} / \AA ̊ \AA$ is close to the initial, DFT-calculated value. Vibrational assignments are listed in Table 2, and the experimental and QCC-NCA simulated NRVS data are compared in Figure 1. All force constants that were fit are listed in Table 3.

The same process was applied to the ls- $\{\mathrm{FeNO}\}^{9}$ and ls- $\{\mathrm{FeNO}\}^{10}$ compounds, and the resulting QCC-NCA simulated NRVS data are compared to experiment in Figure 1. Vibrational assignments are provided in Table 2, and key force constants of the ls$\{\mathrm{FeNO}\}^{8-10}$ series are listed in Tables 1 and 3 . Reduction of the 1s- $\{\mathrm{FeNO}\}^{8}$ to the 1s$\{\mathrm{FeNO}\}^{9}$ complex causes both the FeNO and N-O bonds to become weaker (with force constants decreasing from $4.53 / 12.5$ to $4.15 / 11.3 \mathrm{mdyn} / \mathrm{A}$, respectively), confirming that this unusual drop in both the Fe-NO and $\mathrm{N}-\mathrm{O}$ stretching frequencies is not caused by unforeseen mode mixing.

Whereas this trend is not in agreement with a simple change in $\pi$-backbonding, as discussed above, this type of behavior actually resembles that observed for the hs- $\{\mathrm{FeNO}\}^{7 / 8}$ complexes, $\left[\mathrm{Fe}\left(\mathrm{TMG}_{3} \text { tren }\right)(\mathrm{NO})\right]^{2+/+}$, where reduction leads to a decrease in $\pi$-donation from the ${ }^{3} \mathrm{NO}^{-}$ligand to the hs-Fe center. ${ }^{24}$ Reduction from the ls- $\{\mathrm{FeNO}\}^{9}$ to the ls$\{\mathrm{FeNO}\}^{10}$ state causes a further weakening of the N-O bond (N-O force constant: 11.3 vs $9.79 \mathrm{mdyn} / \AA$ ) ), but at the same time, the Fe-NO bond now becomes stronger (Fe-NO force constant: 4.15 to $4.45 \mathrm{mdyn} / \AA$ ). This is opposite to the trend observed for the $1 \mathrm{~s}-\{\mathrm{FeNO}\}^{8 / 9}$ pair, but in agreement with the trends derived from the vibrational frequencies (see above).

A distinct Fe-B stretching mode is not observed in the experimental NRVS data. Because of this, we were unable to optimize the corresponding Fe-B force constants via the QCC-NCA process, and Table 3 lists the DFT-calculated Fe-B force constants. Nonetheless, the close agreement between the DFT-predicted and the experimental force constants gives us confidence that the Fe-B force constants are accurate $( \pm 10 \%)$.

In the $1 \mathrm{~s}-\{\mathrm{FeNO}\}^{8}$ and ls- $\{\mathrm{FeNO}\}^{9}$ complexes, the Fe-B interaction is relatively weak, with a calculated force constant of $\sim 0.5 \mathrm{mdyn} / \mathrm{A}$. Reduction to the $1 \mathrm{~s}-\{\mathrm{FeNO}\}^{10}$ state then causes a remarkable increase in the $\mathrm{Fe}-\mathrm{B}$ bond strength, with the $\mathrm{Fe}-\mathrm{B}$ force constant increasing to $1.56 \mathrm{mdyn} / \AA$. The data thus suggest that an Fe-B single bond forms in the $1 \mathrm{~s}-\{\mathrm{FeNO}\}^{10}$ state via a reverse dative bond with the Fe center serving as a Lewis base, donating a pair of electrons to the borane Lewis acid. This clearly shows that $\mathrm{d}_{\mathrm{z}} 2$ is doubly occupied in the 1s$\{\text { FeNO }\}^{10}$ state. Relatedly, a dative $\mathrm{B}^{-} \rightarrow \mathrm{Cu}$ bond has previously been identified computationally and spectroscopically in $[\mathrm{Cu}(\mathrm{TPB})]^{-}, 56$ and Fe-B flexibility has been implicated as a key feature in stabilizing $\mathrm{Fe}$ across formal redox states. ${ }^{57,58}$ 


\subsection{Pulse EPR Measurements of the Is- $\{\mathrm{FeNO}\}^{9}$ Complex}

The ls- $\{\mathrm{FeNO}\}^{9}$ complex [Fe(TPB)(NO)] has an $S_{\mathrm{t}}=1 / 2$ ground state and is therefore EPR active. As previously reported, this complex displays an axial EPR signal $(g=1.99,1.99$, 2.45; see Figure S4) with a large $g_{\mathrm{z}}$ value (2.45). This is consistent with the approximate trigonal-bipyramidal geometry of the complex and an electronic structure in which the electron hole is mostly located in the $x y$-plane (with the Fe-NO vector corresponding to the $z$-axis) and on the metal center (directly indicated by the large $g$ shift). This leads to strong $2^{\text {nd }}$ order spin-orbit coupling in the $z$ direction. Indeed, similar axial EPR spectra with large $g_{\mathrm{Z}}$ shifts have been measured for a number of TPB and $\mathrm{P}_{3} \mathrm{Si}$ (features $\mathrm{Si}$ in place of B) complexes with similar electronic structures (i.e., $\mathrm{e}_{\mathrm{g}}{ }^{3}$ ground states) ${ }^{59}$ As these complexes vary primarily in the identity of their axial ligand, information about that Fe-L interaction can be extracted from the $g$-anisotropy. This is further analyzed in the Discussion section, in direct comparison to the isoelectronic $\mathrm{N}_{2}$-adduct $\left[\mathrm{Fe}(\mathrm{TPB})\left(\mathrm{N}_{2}\right)\right]^{-}$.

Interestingly, if we include all $\left(\mathrm{P}_{3} \mathrm{E}\right) \mathrm{Fe}-\mathrm{L}$ complexes $(\mathrm{E}=\mathrm{B}$ in $\mathrm{TPB}, \mathrm{Si})$ with an $\mathrm{e}_{\mathrm{g}}{ }^{3}$ ground state for which an X-ray structure and EPR spectrum has been measured, we find a strong linear correlation between $\Delta g_{\mathrm{Z}}$ and the $\mathrm{Fe}-\mathrm{P}$ distance $\left(\mathrm{R}^{2}=0.92\right)$. This suggests that the covalency of the Fe-P bond and/or the out-of-plane displacement of the Fe center might play a key role in determining $\Delta g_{\mathrm{z}}$. Furthermore, we find that the Fe center in [Fe(TPB)(NO)] has a $\Delta g_{\mathrm{z}}$ that lies between those found for formally $\mathrm{Fe}^{\mathrm{I}}$ and $\mathrm{Fe}^{\mathrm{III}}$ ions in $\left(\mathrm{P}_{3}{ }^{\mathrm{E}}\right) \mathrm{Fe}-\mathrm{L}$ complexes. Given the vibrational and computational data are consistent with an $\mathrm{NO}^{+}$ligand state and thus the $\mathrm{Fe}$ is formally $\mathrm{Fe}^{-\mathrm{I}}$, this demonstrates the tremendous ability of a covalently bonded $\mathrm{NO}^{+}$ligand to accept electron density.

Analysis of X-band hyperfine sublevel correlation (HYSCORE) spectroscopy acquired on samples prepared with natural abundance $\left({ }^{14} \mathrm{~N}\right)$ and ${ }^{15} \mathrm{~N}$ labeled NO bound (see Figure 4) allowed us to accurately determine relatively weak hyperfine coupling constants to the coordinated ${ }^{14 / 15} \mathrm{~N}(\mathrm{O})$ and ${ }^{11} \mathrm{~B}$ centers providing further insight into the electron spin distribution in the complex. The observed coupling to the ${ }^{14} \mathrm{~N}$ nucleus is largely axial consistent with the axial g-tensor observed in the CW EPR measurements. Simulation of the ${ }^{15} \mathrm{~N}$ HYSCORE data allowed for determination of the nitrogen hyperfine coupling tensor as $\mathrm{A}\left({ }^{15} \mathrm{~N}\right)=[8.4,11.6,-5.4] \mathrm{MHz}$, independent of any influence from the nuclear quadrupole interaction present in the natural abundance data due to the presence of the $I=1{ }^{14} \mathrm{~N}$ nucleus. Accounting for the relative gyromagnetic ratios of ${ }^{14 / 15} \mathrm{~N}\left(\gamma^{14} \mathrm{~N} / \gamma^{15} \mathrm{~N}=-0.7129\right)$ the ${ }^{14} \mathrm{~N}$ hyperfine coupling tensor is $\mathrm{A}\left({ }^{14} \mathrm{~N}\right)=[-6.0,-8.3,3.8] \mathrm{MHz}$, which can be decomposed into an isotropic component $a_{\text {iso }}\left({ }^{14} \mathrm{~N}\right)=-3.5 \mathrm{MHz}$ and an anisotropic component of $T\left({ }^{14} \mathrm{~N}\right)=[-2.5,-4.8,7.3] \mathrm{MHz}$. The small $a_{\text {iso }}$ value indicates that minimal spin (estimated: $0.002 \mathrm{e}^{-}$) is an $\mathrm{a}_{1}$-type orbital ( $\mathrm{s}$ or $\mathrm{p}_{\mathrm{z}}$ ) with most spin (estimated: $0.065 \mathrm{e}^{-}$) in the e-symmetric $p_{x}$ and $p_{y}$ set. These results would be consistent with a spin polarization mechanism that transfers electron density from the $\mathrm{d}_{\mathrm{xy}} / \mathrm{d}_{\mathrm{x}}{ }^{2}-\mathrm{y}^{2}$ orbitals into the $\mathrm{p}_{\mathrm{x}} / \mathrm{p}_{\mathrm{y}}$ orbitals of the NO ligand. The total spin density of $-0.07 \mathrm{e}^{-}$on the $\mathrm{N}$ atom is consistent with the DFT predictions for a CS state. Comparison of these hyperfine parameters with those similarly extracted for $\left[\mathrm{Fe}(\mathrm{TPB})\left(\mathrm{NNMe}_{2}\right)\right]^{+/-}$further supports the CS rather than a BS electronic ground state for the $1 \mathrm{~s}-\{\mathrm{FeNO}\}^{9}$ complex. 
Comparison of the HYSCORE data of the ${ }^{14} \mathrm{~N}$ and ${ }^{15} \mathrm{~N}$ isotopologues allows for accurate determination of not only the hyperfine coupling constants, but also the electric interaction of the $I=1{ }^{14} \mathrm{~N}$ nuclear quadrupole with the inhomogeneous electric field induced by electron density in p-orbitals at the nucleus. This interaction is parameterized by the nuclear quadrupole coupling constant $\left(e^{2} q Q / h=0.8\right)$ and the electric field gradient $(\mathrm{EFG})$ asymmetry $(\eta=0)$. The low magnitude of $e^{2} q Q / h$ and negligible EFG rhombicity indicates nearly spherical charge density about the nitrogen nucleus in this complex, in agreement with the linear Fe-N-O unit and equal spin distribution in the $\mathrm{p}_{\mathrm{x}}$ and $\mathrm{p}_{\mathrm{y}}$ orbitals.

The hyperfine coupling to boron with $\mathrm{A}\left({ }^{11} \mathrm{~B}\right)=[14.7,14.7,18.0] \mathrm{MHz}$ can be decomposed into $a_{\mathrm{iso}}\left({ }^{11} \mathrm{~B}\right)=15.8 \mathrm{MHz}$ and a small anisotropic contribution of $T\left({ }^{11} \mathrm{~B}\right)=[-1.1,-1.1,2.2]$ $\mathrm{MHz}$. These data indicate that significantly less electron density is on that ligand $\left(0.006 \mathrm{e}^{-}\right.$ in $\mathrm{a}_{1}$ type orbitals and $0.017 \mathrm{e}^{-}$in e-type orbitals) and are consistent with the DFT results. We interpret these results as being consistent with the lack of available orbitals of appropriate symmetry to accept electron density from the xy-plane via spin polarization. Xband ENDOR experiments to determine the hyperfine coupling to ${ }^{31} \mathrm{P}$ of the phosphine ligands are best modeled with a single class of fairly isotropic coupling constants, $\mathrm{A}\left({ }^{31} \mathrm{P}\right)=$ $[82,70,70] \mathrm{MHz}$, which corresponds to $a_{\text {iso }}\left({ }^{31} \mathrm{P}\right)=74 \mathrm{MHz}$ and an anisotropic component of $T\left({ }^{31} \mathrm{P}\right)=[8,-4,-4] \mathrm{MHz}$. The large hyperfine coupling to the ${ }^{31} \mathrm{P}$ centers again supports the idea that the electron hole is mostly located in the $x y$-plane.

\subsection{Electronic Structure Analysis}

The Is- $\{\mathrm{FeNO}\}^{\mathbf{8}} \mathrm{Complex}$ has eight valence electrons, as indicated by the Enemark-Feltham index, and, as discussed above, the complex has a closed-shell singlet ground state, which means that of the total seven valence MOs $\left(5 \mathrm{Fe}(\mathrm{d})+2 \mathrm{NO}\left(\pi^{*}\right)\right.$ orbitals), four valence MOs are doubly occupied, and three are empty. The MOs themselves are strongly mixed, and Scheme 2 represents a simplified version of the bonding scheme. Here, the Fe-N-O unit corresponds to the molecular $z$-axis. The strong distortion away from $\mathrm{C}_{3}$ symmetry towards a T-shaped geometry in the $\mathrm{FeP}_{3}$ plane, characterized by a large $\mathrm{P}$-Fe-P angle $\left(154^{\circ}\right)$, causes a large energy splitting between the $\mathrm{d}_{\mathrm{xy}}$ and $\mathrm{d}_{\mathrm{x}}{ }^{2}-\mathrm{y}^{2}$ orbitals of $1.97 \mathrm{eV}$, as indicated in

Scheme 3. In this geometry, the lower energy orbital, $d_{x y}$ (HOMO-1), is essentially $\sigma$ nonbonding with respect to the phosphine ligands ( $80 \% \mathrm{Fe}$ character). Whereas, the lowest unoccupied molecular orbital (LUMO), the empty $\mathrm{d}_{\mathrm{x}}{ }^{2}-\mathrm{y}^{2}$ orbital, shows strong antibonding $\left(\sigma^{*}\right)$ interactions with the in-plane phosphine donors (see Scheme 3). Unexpectedly, the $\mathrm{d}_{\mathrm{x}}{ }^{2}-\mathrm{y}^{2}$ orbital also has a strong admixture of one of the $\mathrm{NO}\left(\pi^{*}\right)$ orbitals $(38 \% \mathrm{Fe}, 14 \%$ $\mathrm{NO}$ ), but because the MO is unoccupied, it does not play a role for bonding in the 1s$\{\mathrm{FeNO}\}^{8}$ complex. This type of admixture, however, becomes relevant in the more reduced species.

The highest occupied molecular orbital (HOMO) of the ls- $\{\mathrm{FeNO}\}^{8}$ complex is the doublyoccupied $\mathrm{d}_{\mathrm{z}} 2$ orbital, which has a notable contribution from the unoccupied boron(p)-orbital $(43 \% \mathrm{Fe}, 12 \% \mathrm{~B})$. This leads to a stabilization of the $\mathrm{d}_{\mathrm{z}} 2$ orbital, which normally is the highest energy orbital in a trigonal-bipyramidal coordination geometry. This weak Lewis base $(\mathrm{Fe})$ - Lewis acid (B) interaction (Fe-B force constant: $0.51 \mathrm{mdyn} / \AA$ ) is indicative of a fractional Fe-B bond order. Hence, despite the relatively short Fe-B distance (2.31 $\AA$ ), the 
bonding between the doubly-occupied $\mathrm{d}_{\mathrm{z}^{2}}$ orbital and the unoccupied boron(p)-orbital is reduced by poor orbital overlap resulting from the tilt of the $\mathrm{BC}(\mathrm{Ph})_{3}$ plane away from the Fe-B axis.

The lowest-lying valence orbitals are the doubly-occupied, Fe-NO $\pi$-bonding combinations of the $d_{x z-} \pi^{*}{ }_{x}$ and $d_{y z} \pi^{*}$ orbitals (HOMO-2 and HOMO-3). These bonds are very covalent, with about $60 \% \mathrm{Fe}(\mathrm{d})$ and $30 \% \mathrm{NO}\left(\pi^{*}\right)$ contribution.

Based on this analysis, and assigning MOs to the atom or group with the dominant charge contribution, the ls- $\{\mathrm{FeNO}\}^{8}$ complex can formally be assigned an $\mathrm{Fe}(0)-\mathrm{NO}^{+}$type electronic structure with all 8 valence electrons originating primarily from the $\mathrm{Fe}$ center, and two very strong $\pi$-backbonds with the $\mathrm{NO}^{+}$ligand (consistent with the large $\mathrm{Fe}-\mathrm{NO}$ force constant of $4.53 \mathrm{mdyn} / \AA)$. The presence of an $\mathrm{NO}^{+}$ligand explains the absence of spin polarization in this system. This is similar to six-coordinate ls- $\{\mathrm{FeNO}\}^{6}$ complexes in hemes, which have been shown to have a closed-shell $\mathrm{Fe}(\mathrm{II})-\mathrm{NO}^{+}$type ground state with no spin polarization. ${ }^{48,60}$ In this sense, the FeNO unit in the $1 \mathrm{~s}-\{\mathrm{FeNO}\}^{8}$ complex could be considered an electronic analog to that of heme $1 \mathrm{~s}-\{\mathrm{FeNO}\}^{6}$ complexes, where two additional electrons of the Fe center are stabilized by the $d_{z} 2-B(p)$ interaction. This becomes more evident in the $1 \mathrm{~s}-\{\mathrm{FeNO}\}^{10}$ system (see below).

Finally, the crystal structure of the $1 \mathrm{~s}-\{\mathrm{FeNO}\}^{8}$ complex reveals a unique $\pi$-bond between the iron center and the $\mathrm{C}=\mathrm{C}$ bond of one of the aromatic benzene rings. This interaction is unique in the ls- $\{\mathrm{FeNO}\}^{8}$ complex and explains the observed, significant contributions of phenyl orbitals to the valence MOs in this complex, which complicates the analysis.

However, this interaction does not affect the FeNO moiety significantly.

The Is- $\{\text { FeNO }\}^{9}$ Complex has an EPR-active $S_{\mathrm{t}}=1 / 2$ ground state, which provides additional spectroscopic handles to further interrogate its ground state electronic structure. Due to spin-polarization effects, the $\alpha$ - and $\beta$-spin covalencies differ in the 1s- $\{\mathrm{FeNO}\}^{9}$ complex, which complicates the analysis of its electronic structure. As we might expect based on its more $\mathrm{C}_{3}$-symmetric structure, reduction of the 1 s- $\{\mathrm{FeNO}\}^{8}$ complex results in an orbital ordering more similar to that of a canonical trigonal bipyramid (see Scheme 3). The SOMO of the ls- $\{\mathrm{FeNO}\}^{9}$ complex is the $\mathrm{d}_{\mathrm{x}}{ }^{2}-\mathrm{y}^{2}$ orbital, as indicated in Scheme 4, pointing towards an iron-based reduction (in agreement with the EPR results). Because of this, the Fe-P covalency in the xy-plane is reduced, and the energy splitting between the $d_{x}{ }^{2}-y^{2}$ and $d_{x y}$ orbitals decreases to $1.02 \mathrm{eV}$. Accordingly, the $d_{x y}$ orbital is now higher in energy than the $\mathrm{d}_{\mathrm{z}^{2}}$ orbital, and becomes the SOMO-1. The two lowest energy valence orbitals remain the $\mathrm{Fe}-\mathrm{NO} \pi$-bonding interactions, which again correspond to the bonding combinations of the $d_{x z}$ and $d_{y z}$ orbitals and the $\mathrm{NO}\left(\pi^{*}{ }_{x} / y\right)$ orbitals. Finally, the $d_{z 2}$ orbital is again lowered in energy by the Fe-B interaction. Scheme 4 shows the resulting bonding scheme of the ls- $\{\mathrm{FeNO}\}^{9}$ complex, which points towards an unusual $\mathrm{Fe}(-\mathrm{I})-\mathrm{NO}^{+}$type ground state.

The experimental data show that the $\mathrm{Fe}-\mathrm{NO}$ bond becomes weaker upon reduction of the ls$\{\mathrm{FeNO}\}^{8}$ to the ls- $\{\mathrm{FeNO}\}^{9}$ state, as reflected by a drop of the corresponding Fe-NO force 
constant from 4.53 to $4.15 \mathrm{mdyn} / \AA$ and of the Fe-NO stretch from 610 to $583 \mathrm{~cm}^{-1}$. This indicates a reduction in the covalency of the two Fe-NO $\pi$-bonds in the $1 \mathrm{~s}-\{\mathrm{FeNO}\}^{9}$ state. The DFT calculations underestimate the weakening of the Fe-NO stretch $\left(\Delta=-27 \mathrm{~cm}^{-1}\right.$ experimentally versus $-17 \mathrm{~cm}^{-1}$ by DFT) and the weakening of the $\mathrm{N}-\mathrm{O}$ stretch $(\Delta=-78 \mathrm{~cm}$ ${ }^{-1}$ experimentally versus $-59 \mathrm{~cm}^{-1}$ by DFT). Nonetheless, DFT captures the seemingly counterintuitive trend that the Fe-NO and $\mathrm{N}-\mathrm{O}$ bond both weaken upon reduction.

Due to spin polarization, both Fe-NO $\pi$-bonds are stronger and more covalent in $\beta$-spin compared to $\alpha$-spin, which manifests itself in the appearance of about -0.1 negative spin density on the NO ligand, in the $\pi^{*} \mathrm{x} / \mathrm{y}$ orbitals. This finding is supported by the pulse EPR measurements, showing weak, mostly anisotropic hyperfine coupling with the ${ }^{14} \mathrm{~N}$ atom of the coordinated NO ligand. Based on this finding alone, one would predict that the $\mathrm{N}-\mathrm{O}$ stretch should increase in energy in the reduced complex, but this is not the case experimentally. The reason for the sharp drop in the N-O stretch from 1745 to $1667 \mathrm{~cm}^{-1}$ upon reduction requires an increase in the occupation of the $\mathrm{NO}\left(\pi^{*}{ }_{\mathrm{x} / \mathrm{y}}\right)$ orbitals in the reduced complex, without increasing the Fe-NO bond strength. This in fact is the case. As shown in Scheme 4, both the $\mathrm{d}_{\mathrm{x}^{2}}-\mathrm{y}^{2}$ SOMO (41\% Fe(d) and 4\% NO character) and the doubly-occupied $\mathrm{d}_{\mathrm{xy}}$ orbital $\left(63 \% \mathrm{Fe}(\mathrm{d})\right.$ and $5 \% \mathrm{NO}$ character) of the $1 \mathrm{~s}-\{\mathrm{FeNO}\}^{9}$ complex show a distinct admixture of the $\mathrm{NO}\left(\pi^{*} \mathrm{x} / \mathrm{y}\right)$ orbitals. Occupation of these MOs effectively transfers electron density into the $\mathrm{NO}\left(\pi^{*}{ }^{*} / \mathrm{y}\right)$ orbitals, weakening the $\mathrm{N}-\mathrm{O}$ bond, but without significantly affecting the Fe-NO bond strength. Although one might initially dismiss this orbital interaction as an artefact of DFT, the available data show that this is a real effect. Indeed, it is significant and likely underestimated in the DFT calculations, considering the larger experimental shift in the N-O stretch $\left(\Delta=-78 \mathrm{~cm}^{-1}\right)$ compared to $\Delta=-59 \mathrm{~cm}^{-1}$ predicted by DFT. Using a linear scaling approach, we can roughly estimate from the N-O stretches of free $\mathrm{NO}^{+}\left(2387 \mathrm{~cm}^{-1}\right)$ and $\mathrm{NO}\left(1876 \mathrm{~cm}^{-1} ; \Delta \approx 500 \mathrm{~cm}^{-1}\right)$ that a shift in the $\mathrm{N}$ O stretch of $\sim 80 \mathrm{~cm}^{-1}$ requires an increase in the occupation of the $\mathrm{NO}\left(\pi^{*} \mathrm{x} / \mathrm{y}\right)$ orbitals by 0.16 electrons (assuming similar electronic structures), which is slightly underestimated in the calculations (Loewdin charges for NO: 1s- $\{\mathrm{FeNO}\}^{8}:+0.02$; $1 \mathrm{~s}-\{\mathrm{FeNO}\}^{9}:-0.11, \Delta\left(\mathrm{e}^{-}\right)=$ $0.13)$.

Further support for the importance of spin polarization effects to the bonding in the 1s$\{\mathrm{FeNO}\}^{9}$ complex is that the Fe-B interaction is predicted to be similarly polarized. Except in this case the relevant ligand orbital is $\mathrm{B}\left(\mathrm{p}_{\mathrm{z}}\right)$ with asymmetry in the $\mathrm{d}_{\mathrm{z}}{ }^{2}-\mathrm{B}\left(\mathrm{p}_{\mathrm{z}}\right)$ interaction. This bond is distinctively more covalent in $\beta$-spin $\left(22 \% \mathrm{~B}\left(\mathrm{p}_{\mathrm{z}}\right)\right.$ admixture into $\left.\mathrm{d}_{\mathrm{z}}{ }^{2}\right)$ compared to $a$-spin $\left(10 \% \mathrm{~B}\left(\mathrm{p}_{\mathrm{z}}\right)\right.$ contribution), again resulting in about -0.1 negative spin density on the boron atom. This is supported by the pulse EPR measurements, showing weak hyperfine coupling to the ${ }^{11} \mathrm{~B}$ nucleus with a relatively larger component of its unpaired spin in an $\mathrm{a}_{1}$ type ( $\mathrm{s}$ or $\mathrm{p}_{\mathrm{z}}$ ) orbital. The DFT calculations predict that the Fe-B bond interaction becomes

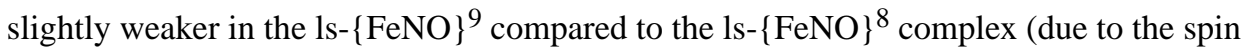
polarization), although in the absence of any vibrational information, it is difficult to confirm this. Therefore, we consider the Fe-B bond to be largely unchanged in the ls- $\{\mathrm{FeNO}\}^{9}$ complex. 
Based on these observations, it is puzzling that despite the iron-based reduction in the ls$\{\mathrm{FeNO}\}^{9}$ relative to the $1 \mathrm{~s}-\{\mathrm{FeNO}\}^{8}$ complex, both the experimental and DFT-calculated Mössbauer isomer shifts only show a very small change (see Table 1). The main reason for this finding is the fact that the occupation of the $\mathrm{d}_{\mathrm{x}}{ }^{2}-\mathrm{y}^{2}$ orbital in the $1 \mathrm{~s}-\{\mathrm{FeNO}\}^{9}$ complex leads to the weakening of the Fe-P interactions, since the $\mathrm{d}_{\mathrm{x}}{ }^{2}-\mathrm{y}^{2}$ orbital is Fe-P antibonding. This is reflected in the corresponding Fe-P force constants, which drop from an average value of $\sim 1.6 \mathrm{mdyn} / \AA$ to $\sim 1.1 \mathrm{mdyn} / \AA ̊$ upon reduction. This decrease in the Fe-P bonding partially compensates for the electron that is added to the $\mathrm{d}_{\mathrm{x}}{ }^{2}-\mathrm{y}^{2}$ orbital, as does the transfer of electron density from the $x y$-plane to the $\mathrm{NO}\left(\pi^{*}\right)$ orbitals (see above). This "redox buffering" causes a negligible change in the effective nuclear charge of the iron center upon reduction, and minimizes the change in the Mössbauer isomer shift.

The Is- $\{\mathrm{FeNO}\}^{10}$ Complex is completely diamagnetic with a CS ground state, as shown in Scheme 5. Compared to the ls- $\{\mathrm{FeNO}\}^{9}$ complex, the extra electron is located in the $\mathrm{d}_{\mathrm{x}}{ }^{2}-\mathrm{y}^{2}$ orbital, completing the $\mathrm{d}^{10}$ shell of the iron center. Therefore, once again, the reduction is iron-centered. As a consequence of the now $\left[\mathrm{d}_{\mathrm{xy}}, \mathrm{d}_{\mathrm{x}}{ }^{2}-\mathrm{y}^{2}\right]^{4}$ electron configuration, the ls$\{\mathrm{FeNO}\}^{10}$ complex adapts an almost perfect trigonal symmetry of the $\mathrm{FeP}_{3}$ unit, causing the $\mathrm{d}_{\mathrm{xy}}$ and $\mathrm{d}_{\mathrm{x}}{ }^{2}-\mathrm{y}^{2}$ orbitals to form a degenerate set (Scheme 3).

In agreement with this analysis, both orbitals show identical charge contributions, with $62 \%$ $\mathrm{Fe}(\mathrm{d})$ character and a $5 \%$ contribution from the $\mathrm{NO}\left(\pi^{*}\right)$ orbitals. Likewise, the lowest lying valence orbitals are also a now degenerate $\mathrm{d}_{\mathrm{xz}} / \mathrm{d}_{\mathrm{yz}}$ pair. This pair shows $53 \% \mathrm{Fe}(\mathrm{d})$ and $38 \%$ $\mathrm{NO}\left(\pi^{*}\right)$ contributions, indicating the presence of a very covalent $\mathrm{Fe}-\mathrm{NO}$ bond, similar to that in the 1s- $\{\mathrm{FeNO}\}^{8}$ complex (60\% Fe and $30 \% \mathrm{NO}$ ). Indeed, the similar orbital contributions of the corresponding $\mathrm{d}_{\mathrm{xz}-} \pi^{*}{ }_{\mathrm{x}}$ and $\mathrm{d}_{\mathrm{yz}-} \pi^{*}{ }_{\mathrm{y}}$ bonding pairs and the similar $\mathrm{Fe}-$ NO force constants of 4.53 and $4.45 \mathrm{mdyn} / \mathrm{A}$ are strongly suggestive of similar Fe-NO bonding interactions in the 1s- $\{\mathrm{FeNO}\}^{8}$ and ls- $\{\mathrm{FeNO}\}^{10}$ complexes. Nonetheless, the N-O stretching frequency in the $1 \mathrm{~s}-\{\mathrm{FeNO}\}^{10}$ complex is $177 \mathrm{~cm}^{-1}$ lower than in the ls- $\{\mathrm{FeNO}\}^{8}$ complex, and the N-O force constant is reduced by about $2.7 \mathrm{mdyn} / \mathrm{A}$. As discussed for the ls- $\{\mathrm{FeNO}\}^{9}$ compound, this is best explained not by increased $\mathrm{Fe}-\mathrm{NO} \pi$-backbonding but rather by the transfer of electron density from the xy-plane into the $\mathrm{NO}\left(\pi^{*}\right)$ orbitals. Indeed, in the ls- $\{\mathrm{FeNO}\}^{10}$ complex, the $\mathrm{d}_{\mathrm{xy}} / \mathrm{d}_{\mathrm{x}}{ }^{2}-\mathrm{y}^{2}$ pair contains $5 \% \mathrm{NO}\left(\pi^{*}\right)$ character each, as indicated in Scheme 5. Once again, this likely represents a lower bound on the magnitude of this effect, given the reduction in the N-O stretching frequency $\left(\Delta_{\exp }=-99 \mathrm{~cm}^{-1}\right.$ vs $\Delta_{\mathrm{DFT}}=$ $-85 \mathrm{~cm}^{-1}$ compared to $\left.1 \mathrm{~s}-\{\mathrm{FeNO}\}^{9}\right)$ is underestimated in the calculations.

Due to the formal $\mathrm{d}^{10}$ configuration, the $\mathrm{Fe}$ center becomes unusually low-valent $(\mathrm{Fe}(-\mathrm{II}))$ in the ls- $\{\mathrm{FeNO}\}^{10}$ complex. However, this charge accumulation on the Fe center is largely compensated by a dramatic strengthening of the $\mathrm{Fe}-\mathrm{B}$ interaction, indicated by the increase in the Fe-B force constant to $1.56 \mathrm{mdyn} / \AA$, which corresponds to the formation of an $\mathrm{Fe}-\mathrm{B} \sigma$ single bond. Here, the iron center becomes a Lewis base and donates one electron pair, located in the doubly-occupied $\mathrm{d}_{\mathrm{z}}^{2}$ orbital, to the boron center, which therefore functions as a Lewis acid in the $1 \mathrm{~s}-\{\mathrm{FeNO}\}^{10}$ complex. This mechanism is key to the stabilization of the $1 \mathrm{~s}-\{\mathrm{FeNO}\}^{10}$ system. Because of the formation of a full Fe-B single bond, the $\mathrm{d}_{\mathrm{z}}{ }^{2}$ orbital 
drops in energy after reduction and is now located significantly below the $d_{x y} / d_{x}{ }^{2}-y^{2}$ degenerate pair. Orbital analysis further reveals that the corresponding (bonding) MO has $35 \% \mathrm{Fe}(\mathrm{d})$ and $23 \% \mathrm{~B}\left(\mathrm{p}_{\mathrm{z}}\right)$ charge contributions (the rest is ligand contribution), in agreement with a very covalent $\mathrm{Fe}-\mathrm{B}$ interaction. Thus, the $1 \mathrm{~s}-\{\mathrm{FeNO}\}^{10}$ complex has an $\mathrm{Fe}(-\mathrm{II})-\mathrm{NO}^{+}$ type electronic structure, but with the electron pair in the $\mathrm{d}_{\mathrm{z}^{2}}$ orbital being strongly stabilized by donation to the boron Lewis acid. In this sense, the ls- $\{\mathrm{FeNO}\}^{10}$ complex contains two non-innocent ligands and could be designated as $1 s-\{\mathrm{BFeNO}\}^{10}$. The NO ligand is more activated due to the aforementioned admixture of $\mathrm{NO}\left(\pi^{*}\right)$ character into the $\mathrm{d}_{\mathrm{xy}} / \mathrm{d}_{\mathrm{x}}{ }^{2}-\mathrm{y}^{2}$ pair.

Curiously, the 1s- $\{\mathrm{FeNO}\}^{10}$ complex has the Fe center with the most positive effective nuclear charge, based on the Mössbauer isomer shift. We attribute the positive isomer shift of the complex relative to the $1 \mathrm{~s}-\{\mathrm{FeNO}\}^{9}$ system to (a) the newly formed Fe-B single bond, which reduces the electron density on the Fe center, and (b) the onset of Fe-P backbonding. Our observations emphasize the uniqueness of the TPB coligand scaffold and its ability to stabilize extremely low-valent metal centers through an adjustable interaction between the metal center and the empty $\mathrm{p}_{\mathrm{z}}$ orbital of boron. Surprisingly, the effect on the N-O bond strength observed for the ls- $\{\mathrm{FeNO}\}^{8}$ and ls- $\{\mathrm{FeNO}\}^{10}$ pair is not so much due to changes in the Fe-NO $\pi$-bond itself, but due to a secondary effect, i.e. the admixture of $\mathrm{NO}\left(\pi^{*}\right)$ character into the $d_{x}{ }^{2}-y^{2 / d_{x y}}$ orbital pair as discussed above.

\section{Discussion}

In previously characterized redox series of Fe-NO complexes, Mössbauer spectroscopy has been a key tool for understanding the redox state of the Fe center. In the cyclam-ac supported Fe-NO series from Wieghardt and coworkers, the change in isomer shift $(\delta)$ across redox states is linear $(\Delta \delta \sim 0.2 \mathrm{~mm} / \mathrm{s}$ per redox state), which has been interpreted in terms of NO-centered redox changes, dramatically affecting the Fe-NO bond and, in turn, the isomer shift. ${ }^{11,31}$ In the $\mathrm{TMG}_{3}$ tren supported Fe-NO series from Lehnert and coworkers even larger changes in the isomer shift are observed $(\Delta \delta \sim 0.4 \mathrm{~mm} / \mathrm{s}$ per redox state), which, in combination with other findings, was taken as evidence of Fe-centered redox changes. ${ }^{24,61}$ More recently, Meyer's hs- $\{\mathrm{FeNO}\}^{7-9}$ series with the TIMEN ${ }^{\mathrm{Mes}}$ coligand has also been shown to follow metal-centered reductions, with changes in isomer shift of $\Delta \delta \sim 0.2 \mathrm{~mm} / \mathrm{s}^{23}$

A direct comparison between the $[\mathrm{Fe}(\mathrm{TPB})(\mathrm{NO})]^{+/ 0 /-}$ and the $\left[\mathrm{Fe}\left(\mathrm{TIMEN}^{\mathrm{Mes}}\right)(\mathrm{NO})\right]^{+/ 0 /-}$ complexes in Figure 6 highlights the stark contrast in stability and reactivity of these lowvalent FeNO systems. ${ }^{62}$ In addition, the FeNO redox series studied here presents a notable difference to the previously reported examples in that the Mössbauer isomer shift does not trend linearly with the redox state of the complex, and the complete range spans less than $0.1 \mathrm{~mm} / \mathrm{s}(0.17-0.26){ }^{32}$ This small overall range speaks to a consistent effective nuclear charge at Fe across our redox series. Similar observations have been reported in a recent study by Moore et al. on a bimetallic Fe-Ti system. In this case, redox-induced changes of the effective neutral charge at Fe are buffered by the Lewis acidic Ti center. Thus, changes in the covalency of the Fe-Ti interaction minimize changes in the isomer shift across the redox series. ${ }^{63}$ The main objective of this study was therefore to interrogate the electronic 
structural changes of the FeNO unit in our $[\mathrm{Fe}(\mathrm{TPB})(\mathrm{NO})]^{+/ 0 /-}$ series, and to identify the origins of the "redox-buffering". For this purpose, we used different spectroscopic methods, especially NRVS and pulse EPR, coupled to DFT calculations.

The 1s- $\{\mathrm{FeNO}\}^{8}$ complex has a low-spin, diamagnetic ground state with Fe-NO and N-O stretching frequencies of 610 and $1745 \mathrm{~cm}^{-1}$. Whereas optimized structures cannot distinguish between possible closed-shell (CS) and broken-symmetry (BS) electronic ground states, the predicted NRVS data (especially the Fe-NO stretch) clearly show that the CS state is the better description of the ground state of the complex (see Figure 2). These findings highlight the unreliability of deriving electronic structural information purely from geometric structures. This reminds us that a bond distance only probes the minimum of a potential energy surface (pes), whereas a vibrational frequency probes the curvature of the pes around the energy minimum, which is a much more sensitive gauge for electronic structure and the strength of a bond. Hence, vibrational data (especially stretching frequencies, in the absence of significant mode-mixing) provide a superior measure of bond strength. The electronic structure of the $1 \mathrm{~s}-\{\mathrm{FeNO}\}^{8}$ complex is best described as $\mathrm{Fe}(0)-\mathrm{NO}$ ${ }^{+}$, with two strong, highly covalent Fe-NO $\pi$-backbonds (see below). The $\mathrm{d}_{\mathrm{z}}{ }^{2}$ orbital is doubly occupied and undergoes a weak but distinct interaction with the boron center, and the LUMO of the complex is the $\mathrm{d}_{\mathrm{x}}{ }^{2}-\mathrm{y}^{2}$ orbital.

Upon one-electron reduction, the $\mathrm{d}_{\mathrm{x}}{ }^{2}-\mathrm{y}^{2}$ orbital becomes singly occupied, leading to an $S_{\mathrm{t}}=$ $1 / 2$ ground state in the $1 \mathrm{~s}-\{\mathrm{FeNO}\}^{9}$ complex. The resulting spin-polarization (directly visible as hyperfine coupling interactions as measured by pulse EPR methods) perturbs both the Fe$\mathrm{NO}$ and Fe-B interactions, which become weaker. This is reflected by a drop in the Fe-NO stretching frequency to $583 \mathrm{~cm}^{-1}$. In the Fe-NO $\pi$-backbonding picture, this should lead to an increase in the $\mathrm{N}-\mathrm{O}$ stretch, but this is counteracted by further occupation of the $\mathrm{NO}\left(\pi^{*}\right)$ orbitals via unusual mixing with the $\mathrm{d}_{\mathrm{x}}{ }^{2}-\mathrm{y}^{2}$ and $\mathrm{d}_{\mathrm{xy}}$ orbitals, which causes the $\mathrm{N}-\mathrm{O}$ stretch to drop to $1667 \mathrm{~cm}^{-1}$.

Lastly, reduction to the diamagnetic $1 \mathrm{~s}-\{\mathrm{FeNO}\}^{10}$ state leads to the double occupation of the $\mathrm{d}_{\mathrm{x}}{ }^{2}-\mathrm{y}^{2}$ orbital. The strength of Fe-NO bond is restored, evident from an increase in the FeNO stretch to $602 \mathrm{~cm}^{-1}$. This increase in Fe-NO $\pi$-backbonding (compared to the ls$\{\mathrm{FeNO}\}^{9}$ complex) as well as the further occupation of the $\mathrm{NO}\left(\pi^{*}\right)$ orbitals (via mixing with the $\mathrm{d}_{\mathrm{xy}} / \mathrm{d}_{\mathrm{x}}{ }^{2}-\mathrm{y}^{2}$ pair) causes a significant drop in the $\mathrm{N}-\mathrm{O}$ stretch to $1568 \mathrm{~cm}^{-1}$. Based on all of these observations, we conclude that the $\mathrm{Fe}-\mathrm{NO} \pi$-bonds are essentially unchanged along the 1s- $\{\mathrm{FeNO}\}^{8-10}$ series. Counterintuitively, the "weak link" in this series is actually the 1s- $\{\mathrm{FeNO}\}^{9}$ complex, due to spin polarization. Importantly, this significant effect of spin polarization on a metal-ligand bond is often proposed but can rarely be directly observed, as in the NO complexes described in this paper.

The $\mathrm{Fe}^{\mathrm{n}}-\mathrm{NO}^{+}(\mathrm{n}=0,-1,-2)$ electronic structure descriptions for our ls- $\{\mathrm{FeNO}\}^{8-10}$ complexes include a very strong $\pi$-backbond, so from a charge perspective the complexes are on average best described as $\mathrm{Fe}^{\mathrm{n}+1}-\mathrm{NO}$ (neutral). Considering that the occupied $\mathrm{d}_{\mathrm{xz}}$ and $\mathrm{d}_{\mathrm{yz}}$ orbitals involved in $\pi$-backbonding have roughly $30-35 \% \mathrm{NO}\left(\pi^{*}\right)$ character, in line with the low $\mathrm{N}-\mathrm{O}$ stretching frequencies of the series, the $\mathrm{Fe}^{\mathrm{n}}-\mathrm{NO}^{+}$description is certainly 
pushed to an extreme here, especially in the 1s- $\{\mathrm{FeNO}\}^{10}$ complex, where the charges are estimated around $\mathrm{Fe}^{-0.6}-\mathrm{NO}^{-0.4}$. Nevertheless, besides applying the IUPAC rule ("the winner takes it all"), we also believe that the $\mathrm{Fe}^{\mathrm{n}}-\mathrm{NO}^{+} /$strong $\pi$-backbond description has merit and is the most accurate representation of the electronic structure of the complexes. The two strong $\pi$-backbonds lead to the transfer of roughly the same amount of $\alpha$ - and $\beta$ spin electron density back from $\mathrm{Fe}^{\mathrm{n}}$ to the $\mathrm{NO}^{+}$ligand (in all complexes), leading to charge accumulation on the NO ligand, without generating any spin (hence, atypically, the ligand is $\mathrm{NO}$ (neutral), but not NO•). Thus, this does not correspond to an actual electron transfer, as an electron has a charge and a spin but rather is an effect of metal-ligand covalency. If an actual electron transfer were to happen, the electronic structure would change to an open shell (BS) ground state like $\mathrm{Fe}^{\mathrm{n}+1}-\mathrm{NO} \bullet$ or $\mathrm{Fe}^{\mathrm{n}+2}-\mathrm{NO}^{-}$, where the $\operatorname{spin}(\mathrm{s})$ of the $\mathrm{NO} \cdot(\mathrm{S}=1 / 2)$ or ${ }^{3} \mathrm{NO}^{-}(\mathrm{S}=1)$ ligand would likely couple antiferromagnetically to the unpaired electrons of the iron center to which the ligand is directly bound. However, as we demonstrate in this paper, such broken symmetry descriptions are not in agreement with the experimental vibrational (NRVS) data, and can therefore be ruled out. This finding is further supported by the pulse EPR data, showing only small ${ }^{14} \mathrm{~N}$ hyperfine coupling constants in the $1 \mathrm{~s}-\{\mathrm{FeNO}\}^{9}$ complex. This difference is not semantic, as our previous work on ferric heme nitrosyls has shown that the closed-shell $\mathrm{Fe}^{\mathrm{n}}-\mathrm{NO}^{+} /$strong $\pi$-backbond versus open shell $\mathrm{Fe}^{\mathrm{n}+1}-\mathrm{NO}$ ground states lead to different electronic properties and $\mathrm{Fe}-\mathrm{NO} / \mathrm{N}-\mathrm{O}$ bond strengths of the complexes. ${ }^{48}$

It is notable and worth emphasizing that although the $\mathrm{d}_{\mathrm{z}}{ }^{2}$ orbital of Fe is doubly occupied throughout the redox series, only the ls- $\{\mathrm{FeNO}\}^{10}$ complex has a strong Fe-B single bond. Thus, iron only adopts a high degree of Lewis base character upon reduction to formal $\mathrm{Fe}(-\mathrm{II})$, not at $\mathrm{Fe}(0)$. Through this reverse dative $\mathrm{Fe} \rightarrow \mathrm{B}$ bond, the redox non-innocent tri(aryl)borane subunit of the TPB ligand system can de facto serve as a redox buffer or electron reservoir by storing two electrons on site (with minimal effect on the Fe-XY bond of an axially coordinated diatomic). In this way, the Fe(TPB) platform shifts the accessible redox states of the complex down by 2 , and the anionic complex can be best described as 1s$\{\mathrm{BFeNO}\}^{10}$. Thus, although the electron density at $\mathrm{Fe}$ is similar in the cationic and anionic complexes, the $\mathrm{NO}$ ligand is far more activated due to the $\mathrm{NO}\left(\pi^{*}\right)$ admixture into the $\mathrm{d}_{\mathrm{xy}} / \mathrm{d}_{\mathrm{x}}{ }^{2}-\mathrm{y}^{2}$ pair. In comparison, the only other known, stable ls- $\{\mathrm{FeNO}\}^{10}$ complex is Hieber's anion, $\left[\mathrm{Fe}(\mathrm{CO})_{3}(\mathrm{NO})\right]^{-} .64-66$ In this case, the three strongly $\pi$-backbonding $\mathrm{CO}$ ligands take on the role of the boron Lewis acid, and allow for the stabilization of the highly reduced iron center in this unusual compound.

We suggest that $\mathrm{Fe} \rightarrow \mathrm{B}$ bond formation should be an important mechanism for storing electrons that can facilitate small molecule functionalization steps, such as axial ligand protonations that oxidize the metal. Such a role has previously been articulated in the context of $\mathrm{N}_{2}$ fixation catalysis mediated by $\mathrm{Fe}(\mathrm{TPB}) .{ }^{57,67}$ However, the key intermediate prior to $\mathrm{N}_{2}$ functionalization, $\left[\mathrm{Fe}(\mathrm{TPB})\left(\mathrm{N}_{2}\right)\right]^{-}$(or $\left\{\mathrm{FeN}_{2}\right\}^{9}$ in analogy to the EnemarkFeltham notation), is isoelectronic to the $1 \mathrm{~s}-\{\mathrm{FeNO}\}^{9}$ complex, and hence might not be expected to have a signficant $\mathrm{Fe} \rightarrow \mathrm{B}$ bond. Both complexes can be described as $\mathrm{Fe}(-\mathrm{I})$ systems with bound $\mathrm{N}_{2}$ and $\mathrm{NO}^{+}$ligands, respectively. 
We therefore evaluated the $\left\{\mathrm{FeN}_{2}\right\}^{9}$ complex by NRVS coupled to QCC-NCA analysis to determine the extent of an $\mathrm{Fe} \rightarrow \mathrm{B}$ interaction (Figure 5). The $\left\{\mathrm{FeN}_{2}\right\}^{9}$ species shows a much weaker Fe-N bond compared to the $1 \mathrm{~s}-\{\mathrm{FeNO}\}^{9}$ complex, with the Fe-NN stretch observed at $488 \mathrm{~cm}^{-1}$ (corresponding to an Fe-N force constant of $2.62 \mathrm{mdyn} / \AA \AA$, compared to 4.15 mdyn/ $/ \AA$ for ls- $\left\{\mathrm{FeNO}^{9}\right\}^{9}$; see Table 3$)$. In turn, a significantly stronger Fe-B interaction is observed in the $\left\{\mathrm{FeN}_{2}\right\}^{9}$ complex (Fe-B force constant 1.21 vs. $0.42 \mathrm{mdyn} / \AA$ ). Thus, the formally $\mathrm{Fe}(-\mathrm{I})$ center is much less stabilized by $\mathrm{N}_{2}$ than by $\mathrm{NO}^{+}$, consistent with their relative $\pi$-accepting abilities. Accordingly, in the $\mathrm{N}_{2}$ complex, formation of an $\mathrm{Fe}-\mathrm{B} \sigma$-bond already occurs at the $\mathrm{d}^{9}$ state. These data provide further support for the hypothesis that $\mathrm{Fe}$ B bonding is critical for achieving productive small molecule functionalization, including $\mathrm{N}_{2}$ fixation, in this system. ${ }^{57,67}$

These observations serve to underscore that the formation of a reverse dative interaction between a transition metal Lewis base and a main group Lewis acid cannot be reliably predicted by formal oxidation states. Thus, even at highly reduced metal centers such as these, there remains significant ambiguity as to whether, and the extent to which, reverse dative interactions form. This ambiguity is often true in ambiphilic ligands, such as TPB, where the relatively soft reverse dative $\mathrm{M} \rightarrow$ Lewis acid (LA) interaction can be dominated by the stronger dative Lewis base $(\mathrm{LB}) \rightarrow \mathrm{M}$ interactions. ${ }^{33-35,68,69,70}$

Although the presence of Fe-B interactions in the ls- $\{\mathrm{FeNO}\}^{8-10} /\left\{\mathrm{FeN}_{2}\right\}^{9}$ complexes cannot be directly observed in the NRVS data, internal calibration of the DFT predicted Fe$\mathrm{B}$ force constants using the experimentally validated $\mathrm{Fe}-\mathrm{N}$ and $\mathrm{Fe}-\mathrm{P}$ interactions provides significant confidence in the theoretical predictions. Furthermore, the formation of an Fe-B bond in the 1s- $\{\mathrm{FeNO}\}^{10}$ complex is supported by the significant upfield shift of the ${ }^{11} \mathrm{~B}$ NMR chemical shift relative to the $1 \mathrm{~s}-\{\mathrm{FeNO}\}^{8}$ species (19.9 ppm vs $\left.36.6 \mathrm{ppm}\right) .{ }^{32}$ These predictions run counter to the expectations based on a simple geometric analysis and led us to evaluate how predicted Fe-B force constants correlate with more typically used geometric measures of $\mathrm{M} \rightarrow \mathrm{LA}$ bonding, the M-LA distance and the degree of pyramidalization at the LA. $^{35}$

In the ls- $\{\mathrm{FeNO}\}^{8-10}$ series, the $\mathrm{Fe}-\mathrm{B}$ distance is by far the shortest in $1 \mathrm{~s}-\{\mathrm{FeNO}\}^{8}$ and is identical, within error, in the ls- $\{\mathrm{FeNO}\}^{9 / 10}$ congeners. Nonetheless, the $1 \mathrm{~s}-\{\mathrm{FeNO}\}^{10}$ complex has a significantly larger Fe-B force constant $\left(1.56 / 0.41 / 0.52\right.$ for $1 \mathrm{~s}-\{\mathrm{FeNO}\}^{10 / 9 / 8}$; see Table 3). The short Fe-B distance in $1 s-\{\mathrm{FeNO}\}^{8}$ is a result of the aforementioned $\eta^{4}$ $\mathrm{BCCP} \rightarrow \mathrm{Fe}$ interaction, a reminder that even in highly related complexes the M-LA distance can be a poor measure of the $\mathrm{M} \rightarrow$ LA bonding.

Similarly, although both $\left[\mathrm{Fe}(\mathrm{TPB})\left(\mathrm{N}_{2}\right)\right]^{-}\left(f_{\mathrm{Fe}-B}=1.21 \mathrm{mdyn} / \AA ̊ \AA\right)$ and $[\mathrm{Fe}(\mathrm{TPB})(\mathrm{NO})]^{-}\left(f_{\mathrm{Fe}-B}\right.$ $=1.56 \mathrm{mdyn} / \AA)$ feature significant pyramidalization at boron $\left(\Sigma\left(<_{\mathrm{CBC}}\right)=332.0^{\circ}\right.$, and $\left.331.0^{\circ}\right)$, an identical degree of pyramidalization is also observed in $\left[\mathrm{Fe}(\mathrm{TPB})\left(\mathrm{NNMe}_{2}\right)\right]^{-}$ $\left.\Sigma\left(<_{\mathrm{CBC}}\right)=332.1^{\circ}\right)$; nonetheless, the latter features a much weaker Fe-B bond $\left(f_{\mathrm{Fe}-\mathrm{B}}=0.44\right.$ mdyn/ $/{ }^{4} .{ }^{45}$ Just as structural comparisons were insufficient to differentiate between CS and BS wavefunctions, they are insufficient for evaluating the $\mathrm{Fe} \rightarrow \mathrm{B}$ interaction. While other spectroscopic techniques, such as NMR and pulse EPR, can provide insight into $\mathrm{M} \rightarrow \mathrm{LA}$ bonding, vibrational spectroscopy provides a powerful tool to directly interrogate such 
interactions without the limitations of spin selection rules. In combination with theoretical methods, this enables a thorough mapping of the degree of $\mathrm{M} \rightarrow \mathrm{LA}$ bonding.

Since both the 1s- $\{\mathrm{FeNO}\}^{9}$ and $\left\{\mathrm{FeN}_{2}\right\}^{9}$ complexes have paramagnetic $S_{\mathrm{t}}=1 / 2$ ground states, further comparisons on their electronic structures can be made using EPR spectroscopy. Based on this work and previous DFT studies, the SOMO of both complexes is the $d_{x}{ }^{2}-y^{2}$ orbital, with a $d^{9}$ valence electron configuration. ${ }^{36}$ This situation is analogous to tetragonal $\mathrm{Cu}$ (II) complexes, and one might therefore expect a large $g_{\mathrm{z}}$ value to originate from spin-orbit coupling (SOC) in the z-direction between the ground state and the $\mathrm{d}_{\mathrm{xy}}$ excited state. This is in fact the case, but interestingly, the $g$-tensor of the $\mathrm{NO}^{+}$complex $(g=$ $1.99,1.99,2.45)$ is significantly more axial (larger $\Delta g_{\mathrm{z}}$ ) than that of the $\mathrm{N}_{2}$ complex ( $g=$ $2.04,2.04,2.31)$. Based on the usual $2^{\text {nd }}$ order SOC formalism, ${ }^{71,72}$ the larger $\Delta g_{\mathrm{Z}}$ shift of the ls- $\{\mathrm{FeNO}\}^{9}$ complex can result from three possibilities: (a) a distinctly larger spin-orbit coupling constant (which is unlikely), (b) a smaller covalency factor for the $\mathrm{d}_{\mathrm{x}}{ }^{2}-\mathrm{y}^{2}$ and $\mathrm{d}_{\mathrm{xy}}$ orbitals, or (c) a reduction in the energy splitting between the $d_{x} 2-y^{2}$ and $d_{x y}$ orbitals.

From the crystal structures, we observe a greater out-of-plane shift for the Fe center in the $\mathrm{NO}^{+}$complex, which could reduce the $\mathrm{d}_{\mathrm{x}}{ }^{2}-\mathrm{y}^{2} / \mathrm{d}_{\mathrm{xy}}$ energy splitting and, in this way, increase the $\mathrm{g}$ shift. However, this possibility is not supported by the DFT calculations, which show a very similar energy gap between the $\mathrm{d}_{\mathrm{x}}{ }^{2}-\mathrm{y}^{2}$ and the $\mathrm{d}_{\mathrm{xy}}$ orbital $(1.02 \mathrm{vs} .0 .96 \mathrm{eV}) .{ }^{73}$ On the other hand, the DFT calculations point to substantially different orbital covalencies for $\mathrm{d}_{\mathrm{x}}^{2}-\mathrm{y}^{2}$ in these complexes $\left(50 \% \mathrm{~d}_{\mathrm{x}}{ }^{2}-\mathrm{y}^{2}\right.$ character in the $\mathrm{N}_{2}$ compared to $63 \%$ in the $\mathrm{NO}^{+}$ complex). Using these numbers and starting from $g_{\mathrm{Z}}=2.45$ in the ls- $\{\mathrm{FeNO}\}^{9}$ complex, the $g_{\mathrm{Z}}$ value for the $\left\{\mathrm{FeN}_{2}\right\}^{9}$ complex would be predicted to be 2.35 , in very good agreement with experiment. Based on this result, we conclude that the differential covalency of the $\mathrm{d}_{\mathrm{x}}{ }^{2}-\mathrm{y}^{2}$ orbital is to a large degree responsible for the difference in $g_{\mathrm{z}}$ values between these complexes.

In summary, the EPR data further support the notion of an approximate $\mathrm{d}^{9}$ ground state in the $1 \mathrm{~s}-\{\mathrm{FeNO}\}^{9}$ and $\left\{\mathrm{FeN}_{2}\right\}^{9}$ complexes, where the larger $g_{\mathrm{z}}$ shift in the former complex is due to the much stronger Fe-NO compared to the Fe-NN bond (evident from the corresponding stretching frequencies), causing a larger out-of-plane displacement of the iron center in the $\mathrm{NO}^{+}$complex, and affecting the metal-ligand covalencies in the $x y$-plane.

\section{Conclusions}

The electronic descriptions developed here for the ls- $\{\mathrm{FeNO}\}^{8-10}$ series are in agreement with all available spectroscopic data, and emphasize the special role of the TPB ligand in allowing for the storage of two electrons in the Fe-B bond, enabling the Fe(TPB) complex to reach a very low oxidation state while allowing for the utilization of these two extra electrons for reductive catalysis. This complements the more conventional approach in small molecule model chemistry of storing electrons in the $\pi^{*}$ orbitals of supporting ligands with extended $\pi$-systems. A prominent example for this approach is the bis(imino)pyridine ligand platform, shown in Figure 7, left. ${ }^{74,75}$ These approaches are reminiscent of that used by Nature, in which larger metalloclusters, such as Fe-S cluster, are electron-loaded before 
activating small molecules. Prominent examples of this strategy include the nitrogenase and CO dehydrogenase enzymes (see Figure 7, right). ${ }^{76-79}$ While in the case of Fe(TPB) a very low formal oxidation state at $\mathrm{Fe}$ must be reached in order for the borane to adopt this special role, tuning of $\mathrm{M} \rightarrow \mathrm{LA}$ interactions potentially provides a route to small molecule activation under milder conditions.

\section{Supplementary Material}

Refer to Web version on PubMed Central for supplementary material.

\section{ACKNOWLEDGMENTS}

This work was supported by grants from the National Science Foundation (CHE-1608331 and CHE-2002855 to NL) and the National Institutes of Health (GM 070757 to JCP). HTD acknowledges support from the Eastman Summer Research Fellowship and the Robert W. Parry Scholarship. MJC acknowledges support from the Resnick Sustainability Institute at Caltech. The Caltech EPR facility was supported by the Dow Next Generation Educator Fund.

\section{References}

1. Ignarro L Nitric Oxide: Biology and Pathobiology; Academic Press: San Diego, 2000.

2. Lehnert N; Berto TC; Galinato MGI; Goodrich LE In The Role of Heme-Nitrosyls in the Biosynthesis, Transport, Sensing, and Detoxification of Nitric Oxide (NO) in Biological Systems: Enzymes and Model Complexes; Kadish KM, Smith KM, Guilard R, Eds.; World Scientific: New Jersey, 2011; Vol. 14,, p 1-247

3. Wink DA; Mitchell JB Chemical biology of nitric oxide: insights into regulatory, cytotoxic, and cytoprotective mechanisms of nitric oxide. Free Rad. Biol. Med 1998, 25, 434-456. [PubMed: 9741580]

4. Bykov D; Neese F Six-Electron Reduction of Nitrite to Ammonia by Cytochrome c Nitrite Reductase: Insights from Density Functional Theory Studies. Inorg. Chem 2015, 54, 9303-9316. [PubMed: 26237518]

5. Ferousi C; Majer SH; DiMucci IM; Lancaster KM Biological and Bioinspired Inorganic N-N BondForming Reactions. Chem. Rev 2020.

6. Fields S Global Nitrogen: Cycling out of Control. Environ Health Perspect 2004, 112, A556-A563. [PubMed: 15238298]

7. Lancaster KM; Caranto JD; Majer SH; Smith MA Alternative Bioenergy: Updates to and Challenges in Nitrification Metalloenzymology. Joule 2018, 2, 421-441.

8. Lehnert N; Dong HT; Harland JB; Hunt AP; White CJ Reversing Nitrogen Fixation. Nat. Rev. Chem 2018, 2, 278-289.

9. Averill BA Dissimilatory Nitrite and Nitric Oxide Reductases. Chem. Rev 1996, 96, 2951-2964. [PubMed: 11848847]

10. Moura I; Moura JJG Structural Aspects of Denitrifying Enzymes. Curr. Opin. Chem. Biol 2001, 5, 168-175. [PubMed: 11282344]

11. Speelman A; Lehnert N Heme versus Non-Heme Iron-Nitroxyl $\{\mathrm{FeN}(\mathrm{H}) \mathrm{O}\}^{8}$ Complexes: Electronic Structure and Biologically Relevant Reactivity. Acc. Chem. Res 2014, 47, 1106-1116. [PubMed: 24555413]

12. Wasser IM; de Vries S; Moënne-Loccoz P; Schröder I; Karlin KD Nitric Oxide in Biological Denitrification: $\mathrm{Fe} / \mathrm{Cu}$ Metalloenzymes and Metal Complex NOx Redox Chemistry. Chem. Rev 2002, 102, 1201-1234. [PubMed: 11942794]

13. Hayashi T; Caranto JD; Wampler DA; Kurtz DM Jr.; Moënne-Loccoz P Insights into the Nitric Oxide Reductase Mechanism of Flavodiiron Proteins from a Flavin-Free Enzyme. Biochemistry 2010, 49, 7040-7049. [PubMed: 20669924] 
14. Silaghi-Dumitrescu R; Coulter ED; Das A; Ljungdahl LG; Jameson GNL; Huynh BH; Kurtz DM Jr. A flavodiiron protein and high molecular weight rubredoxin from Moorella thermoacetica with nitric oxide reductase activity. Biochemistry 2003, 42, 2806-2815. [PubMed: 12627946]

15. Khatua S; Majumdar A Flavodiiron Nitric Oxide Reductases: Recent Developments in the Mechanistic Study and Model Chemistry for the Catalytic Reduction of NO. J. Inorg. Biochem 2015, 142, 145-153. [PubMed: 25458587]

16. Lehnert N; Fujisawa K; Camarena S; Dong HT; White CJ Activation of Non-Heme Iron-Nitrosyl Complexes: Turning up the Heat. ACS Catal 2019, 9, 10499-10518.

17. Enemark JH; Feltham RD Principles of Structure, Bonding, and Reactivity for Metal Nitrosyl Complexes. Coord. Chem. Rev 1974, 13, 339-406.

18. Caranto JD; Weitz A; Giri N; Hendrich MP; Kurtz DMJ A Diferrous-Dinitrosyl Intermediate in the $\mathrm{N}_{2} \mathrm{O}$-Generating Pathway of a Deflavinated Flavo-Diiron Protein. Biochemistry 2014, 53, 56315637. [PubMed: 25144650]

19. Caranto JD; Weitz A; Hendrich MP; Kurtz DM Jr. The Nitric Oxide Reductase Mechanism of a Flavo-Diiron Protein: Identification of Active-Site Intermediates and Products. J. Am. Chem. Soc 2014, 136, 7981-7992. [PubMed: 24828196]

20. Van Stappen C; Lehnert N Mechanism of N-N Bond Formation by Transition Metal-Nitrosyl Complexes: Modeling Flavodiiron Nitric Oxide Reductases. Inorg. Chem 2018, 57, 4252-4269. [PubMed: 29608298]

21. Confer AM; McQuilken AC; Matsumura H; Moënne-Loccoz P; Goldberg DP A Nonheme, HighSpin $\{\text { FeNO }\}^{8}$ Complex that Spontaneously Generates $N_{2}$ O. J. Am. Chem. Soc 2017, 139, 1062110624. [PubMed: 28749673]

22. Fujisawa K; Soma S; Kurihara H; Ohta A; Dong HT; Minakawa Y; Zhao J; Alp EE; Hu MY; Lehnert N Stable Ferrous Mononitroxyl $\{\mathrm{FeNO}\}^{8}$ Complex with a Hindered Hydrotris(pyrazolyl)borate Coligand: Structure, Spectroscopic Characterization, and Reactivity Toward NO and O2. Inorg. Chem 2019, 58, 4059-4062. [PubMed: 30864791]

23. Keilwerth M; Hohenberger J; Heinemann FW; Sutter J. r.; Scheurer A; Fang H; Bill E; Neese F; Ye $\mathrm{S}$; Meyer K A Series of Iron Nitrosyl Complexes $\{\mathrm{Fe}-\mathrm{NO}\}^{6-9}$ and a Fleeting $\{\mathrm{Fe}-\mathrm{NO}\}^{10}$ Intermediate en Route to a Metalacyclic Iron Nitrosoalkane. J. Am. Chem. Soc 2019, 141, 1721717235. [PubMed: 31566964]

24. Speelman AL; White CJ; Zhang B; Alp EE; Zhao J; Hu M; Krebs C; Penner-Hahn J; Lehnert N Non-heme High-Spin $\{\mathrm{FeNO}\}^{6-8}$ Complexes: One Ligand Platform Can Do It All. J. Am. Chem. Soc 2018, 140, 11341-11359. [PubMed: 30107126]

25. Dong HT; White CJ; Zhang B; Krebs C; Lehnert N Non-Heme Diiron Model Complexes Can Mediate Direct NO Reduction: Mechanistic Insight into Flavodiiron NO Reductases. J. Am. Chem. Soc 2018, 140, 13429-13440. [PubMed: 30220202]

26. Zheng S; Berto TC; Dahl EW; Hoffman MB; Speelman AL; Lehnert N The Functional Model Complex [Fe2(BPMP)(OPr)(NO)2](BPh4)2 Provides Insight into the Mechanism of Flavodiiron NO Reductases. J. Am. Chem. Soc 2013, 135, 4902-4905. [PubMed: 23472831]

27. Jana M; Pal N; White CJ; Kupper C; Meyer F; Lehnert N; Majumdar A Functional Mononitrosyl Diiron(II) Complex Mediates the Reduction of NO to N2O with Relevance for Flavodiiron NO Reductases. J. Am. Chem. Soc 2017, 140, 14380-14383.

28. Dong HT; Speelman AL; Kozemchak CE; Sil D; Krebs C; Lehnert N The $\mathrm{Fe}_{2}(\mathrm{NO})_{2}$ Diamond Core: A Unique Structural Motif in Non-Heme Iron-NO Chemistry. Angew. Chem. Int. Ed 2019, 131, 17859-17863.

29. Ye S; Price JC; Barr EW; Green MT; Bollinger JM; Krebs C; Neese F Cryoreduction of the NOAdduct of Taurine: a-Ketoglutarate Dioxygenase (TauD) Yields an Elusive $\{$ FeNO 8 Species. J. Am. Chem. Soc 2010, 132, 4739-4751. [PubMed: 20218714]

30. Ng TL; Rohac R; Mitchell AJ; Boal AK; Balskus EP An N-nitrosating Metalloenzyme Constructs the Pharmacophore of Streptozotocin. Nature 2019, 566, 94-99. [PubMed: 30728519]

31. Serres RG; Grapperhaus CA; Bothe E; Bill E; Weyhermüller T; Neese F; Wieghardt K Structural, Spectroscopic, and Computational Study of an Octahedral, Non-Heme $\{\mathrm{Fe}-\mathrm{NO}\}^{6-8}$ Series: $[\mathrm{Fe}(\mathrm{NO})(\mathrm{cyclam}-\mathrm{ac})]^{2 /+++/ 0}$. J. Am. Chem. Soc 2004, 126, 5138-5153. [PubMed: 15099097] 
32. Chalkley MJ; Peters JC A Triad of Highly Reduced, Linear Iron Nitrosyl Complexes: $\{\text { FeNO }\}^{8-10}$. Angew. Chem. Int. Ed 2016, 55, 11995-11998.

33. Jones JS; Gabbaï FP Coordination- and Redox-Noninnocent Behavior of Ambiphilic Ligands Containing Antimony. Acc. Chem. Res 2016, 49, 857-867. [PubMed: 27092722]

34. Braunschweig H; Dewhurst RD Transition metals as Lewis bases: "Z-type" boron ligands and metal-to-boron dative bonding. Dalton Trans 2011, 40, 549-558. [PubMed: 21116564]

35. Bouhadir G; Bourissou D In The Chemical Bond III: 100 years old and getting stronger; Mingos DMP, Ed.; Springer International Publishing: Cham, 2017, p 141-201.

36. Vyas N; Kumar A; Ojha AK; Grover A Electronic structure of iron dinitrogen complex [(TPB)FeN2] 2-/1-/0: correlation to Mössbauer parameters. RSC Adv 2020, 10, 7948-7955.

37. Stoll S; Schweiger A EasySpin, a comprehensive software package for spectral simulation and analysis in EPR. J. Magn. Reson 2006, 178, 42-55. [PubMed: 16188474]

38. Hyde JS; Pasenkiewicz-Gierula M; Jesmanowicz A; Antholine WE Pseudo field modulation in EPR spectroscopy. Appl. Magn. Reson 1990, 1, 483.

39. Frisch MJ; Trucks GW; Schlegel HB; Scuseria GE; Robb MA; Cheeseman JR; Scalmani G; Barone V; Mennucci B; Petersson GA; Nakatsuji H; Caricato M; Li X; Hratchian HP; Izmaylov AF; Bloino J; Zheng G; Sonnenberg JL; Hada M; Ehara M; Toyota K; Fukuda R; Hasegawa J; Ishida M; Nakajima T; Honda Y; Kitao O; Nakai H; Vreven T; Montgomery JA; Peralta JE; Ogliaro F; Bearpark M; Heyd JJ; Brothers E; Kudin KN; Staroverov VN; Kobayashi R; Normand J; Raghavachari K; Rendell A; Burant JC; Iyengar SS; Tomasi J; Cossi M; Rega N; Millam JM; Klene M; Knox JE; Cross JB; Bakken V; Adamo C; Jaramillo J; Gomperts R; Stratmann RE; Yazyev O; Austin AJ; Cammi R; Pomelli C; Ochterski JW; Martin RL; Morokuma K; Zakrzewski VG; Voth GA; Salvador P; Dannenberg JJ; Dapprich S; Daniels AD; Farkas; Foresman JB; Ortiz JV; Cioslowski J; Fox DJ Gaussian 09, Revision B.01. Wallingford CT 2009.

40. Praneeth VKK; Näther C; Peters G; Lehnert N Spectroscopic Properties and Electronic Structure of Five- and Six-Coordinate Iron(II) Porphyrin NO Complexes: Effect of the Axial N-Donor Ligand. Inorg. Chem 2006, 45, 2795-2811. [PubMed: 16562937]

41. Neese F The ORCA program system. Wiley Interdisciplinary Reviews: Computational Molecular Science 2011, 2, 73-78.

42. Mingos DMP Nitrosyl Complexes in Inorganic Chemistry, Biochemistry and Medicine II; Springer-Verlag Berlin Heidelberg, 2014; Vol. 154.

43. McQuarters AB; Kampf JW; Alp EE; Hu M; Zhao J; Lehnert N Ferric Heme-Nitrosyl Complexes: Kinetically Robust or Unstable Intermediates? Inorg. Chem 2017, 56, 10513-10528. [PubMed: 28825299]

44. Soldatova AV; Ibrahim M; Olson JS; Czernuszewicz RS; Spiro TG New Light on NO Bonding in $\mathrm{Fe}$ (III) Heme Proteins from Resonance Raman Spectroscopy and DFT Modeling. J. Am. Chem. Soc 2010, 132, 4614-4625. [PubMed: 20218710]

45. Thompson NB; Oyala PH; Dong HT; Chalkley MJ; Zhao J; Alp EE; Hu M; Lehnert N; Peters JC Electronic Structures of an $[\mathrm{Fe}(\mathrm{NNR} 2)]^{+/ 0 /-}$ Redox Series: Ligand Noninnocence and Implications for Catalytic Nitrogen Fixation. Inorg. Chem 2019, 58, 3535-3549. [PubMed: 30762355]

46. Lehnert N; Galinato MGI; Paulat F; Richter-Addo GB; Sturhahn W; Xu N; Zhao J Nuclear Resonance Vibrational Spectroscopy applied to [Fe(OEP)(NO)]: the Vibrational Assignments of Five-Coordinate Ferrous Heme Nitrosyls and Implications for Electronic Structure. Inorg. Chem 2010, 49, 4133-4148. [PubMed: 20345089]

47. Goodrich LE; Paulat F; Praneeth VKK; Lehnert N Electronic Structure and Reactivity of HemeNitrosyls and Its Significance for Nitric Oxide Sensing, Transport, and Catalysis in Biological Systems. Inorg. Chem 2010, 49, 6293-6316. [PubMed: 20666388]

48. Praneeth VKK; Paulat F; Berto TC; DeBeer George S; Näther C; Sulok CD; Lehnert N Electronic Structure of Six-Coordinate Iron(III)-Porphyrin NO Adducts: the Elusive Iron(III)-NO(radical) State and Its Influence on the Properties of these Complexes. J. Am. Chem. Soc 2008, 130, 1528815303. [PubMed: 18942830]

49. Soma S; Van Stappen C; Kiss M; Szilagyi RK; Lehnert N; Fujisawa K Distorted Tetrahedral Nickel-Nitrosyl Complexes: Spectroscopic Characterization and Electronic Structure. J. Biol. Inorg. Chem 2016, 21, 757-775. [PubMed: 27350153] 
50. Hunt AP; Lehnert N The Thiolate Trans Effect in Heme $\{\mathrm{FeNO}\}^{6}$ Complexes and Beyond: Insight into the Nature of the Push Effect. Inorg. Chem 2019, 58, 11317-11332. [PubMed: 30912445]

51. Fujisawa K; Soma S; Kurihara H; Dong HT; Bilodeau M; Lehnert N A cobalt-nitrosyl complex with a hindered hydrotris(pyrazolyl)borate coligand: detailed electronic structure, and reactivity towards dioxygen. Dalton Trans 2017, 46, 13273-13289. [PubMed: 28749492]

52. Van Stappen C; Lehnert N Mechanism of N-N Bond Formation by Transition Metal-Nitrosyl Complexes: Modeling Flavodiiron Nitric Oxide Reductases. Inorg. Chem 2018, 57, 4252-4269. [PubMed: 29608298]

53. Berto TC; Hoffman MB; Murata Y; Landenberger KB; Alp EE; Zhao J; Lehnert N Structural and Electronic Characterization of Non-Heme Fe(II)-Nitrosyls as Biomimetic Models of the FeB Center of Bacterial Nitric Oxide Reductase (NorBC). J. Am. Chem. Soc 2011, 133, 16714-16717. [PubMed: 21630658]

54. Berto TC; Speelman A; Zheng S; Lehnert N Mono- and Dinuclear Non-Heme Iron-Nitrosyl Complexes: Models for Key Intermediates in Bacterial Nitric Oxide Reductases. Coord. Chem. Rev 2013, 257, 244-259.

55. Lehnert N In Computational Inorganic and Bioinorganic Chemistry; John Wiley \& Sons, Chichester, UK: Encyclopedia of Inorganic Chemistry, 2009; Vol. 2009, p 123-140.

56. Moret M-E; Zhang L; Peters JC A Polar Copper-Boron One-Electron $\sigma$-Bond. J. Am. Chem. Soc 2013, 135, 3792-3795. [PubMed: 23418750]

57. Thompson NB; Green MT; Peters JC Nitrogen Fixation via a Terminal Fe(IV) Nitride. J. Am. Chem. Soc 2017, 139, 15312-15315. [PubMed: 28992418]

58. Moret M-E; Peters JC N 2 Functionalization at Iron Metallaboratranes. J. Am. Chem. Soc 2011, 133, 18118-18121. [PubMed: 22008018]

59. Gunderson WA; Suess DLM; Fong H; Wang X; Hoffmann CM; Cutsail Iii GE; Peters JC; Hoffman BM Free $\mathrm{H}_{2}$ Rotation vs Jahn-Teller Constraints in the Nonclassical Trigonal (TPB)Co-H2 Complex. J. Am. Chem. Soc 2014, 136, 14998-15009. [PubMed: 25244422]

60. McQuarters AB; Kampf J; Alp EE; Hu MY; Zhao J; Lehnert N Ferric Heme-Nitrosyl Complexes: Kinetically Robust or Unstable Intermediates? Inorg. Chem 2017, 56, 10513-10528. [PubMed: 28825299]

61. Speelman A; Zhang B; Krebs C; Lehnert N Structural and Spectroscopic Characterization of a High-Spin $\{\mathrm{FeNO}\}^{6}$ Complex with an Iron(IV)-NO ${ }^{-}$Electronic Structure. Angew. Chem. Int. Ed 2016, 55, 6685-6688.

62. In particular, while the putative $\{\mathrm{FeNO}\}^{10}$ complex, [Fe(TIMENMes)(NO) $]^{-}$, immediately undergoes $\mathrm{N}$ insertion into one of the iron carbene bonds of the NHC coligand, the $1 \mathrm{~s}-\{\mathrm{FeNO}\}^{10}$ complex, $[\mathrm{Fe}(\mathrm{TPB})(\mathrm{NO})]^{-}$, is stable. This is in agreement with the findings from the NRVS data, which show that the $[\mathrm{Fe}(\mathrm{TPB})(\mathrm{NO})]^{+/ 0 /-}$ complexes all have very strong $\mathrm{Fe}-\mathrm{NO}$ bonds, with corresponding Fe-NO stretching frequencies in the $600 \mathrm{~cm}^{-1}$ range, and corresponding $\mathrm{Fe}-\mathrm{NO}$ force constants $>4$ mdyn/ ̊. .

63. Moore JT; Chatterjee S; Tarrago M; Clouston LJ; Sproules S; Bill E; Bernales V; Gagliardi L; Ye S; Lancaster KM; Lu CC Enhanced Fe-Centered Redox Flexibility in Fe-Ti Heterobimetallic Complexes. Inorg. Chem 2019, 58, 6199-6214. [PubMed: 30957996]

64. Burkhardt L; Vukadinovic Y; Nowakowski M; Kalinko A; Rudolph J; Carlsson P-A; Jacob CR; Bauer M Electronic Structure of the Hieber Anion $\left[\mathrm{Fe}(\mathrm{CO})_{3}(\mathrm{NO})\right]^{-}$Revisited by X-ray Emission and Absorption Spectroscopy. Inorg. Chem 2020, 59, 3551-3561.

65. Hieber W; Beutner K Notizen: Über Nitrosyltricarbonylferrat $(-\mathrm{I}),\left[\mathrm{Fe}(\mathrm{CO})_{3} \mathrm{NO}\right]^{\ominus}$. Zeitschrift für Naturforschung B 1960, 15, 323-324.

66. Klein JEMN; Miehlich B; Holzwarth MS; Bauer M; Milek M; Khusniyarov MM; Knizia G; Werner H-J; Plietker B The Electronic Ground State of $\left[\mathrm{Fe}(\mathrm{CO})_{3}(\mathrm{NO})\right]^{-}$: A Spectroscopic and Theoretical Study. Angew. Chem. Int. Ed 2014, 53, 1790-1794.

67. Anderson JS; Rittle J; Peters JC Catalytic conversion of nitrogen to ammonia by an iron model complex. Nature 2013, 501, 84-87. [PubMed: 24005414]

68. Hill AF An Unambiguous Electron-Counting Notation for Metallaboratranes. Organometallics 2006, 25, 4741-4743. 
69. Parkin G A Simple Description of the Bonding in Transition-Metal Borane Complexes. Organometallics 2006, 25, 4744-4747.

70. Bouhadir GB,D In Ligand Design in Metal Chemistry; Vol. 2016, p 237-269.

71. Both complexes show strongly Jahn-Teller (JT) distorted ground states which quenches residual orbital angular momentum and annihilates in-state SOC. Based on an in-depth analysis on pseudoJT coupling in trigonal Mo-based $\mathrm{d}^{1}$ systems, it was shown that in such cases second-order SOC is sufficient to analyze the EPR $g$ tensor.

72. Sharma A; Roemelt M; Reithofer M; Schrock RR; Hoffman BM; Neese F EPR/ENDOR and Theoretical Study of the Jahn-Teller-Active [HIPTN3N]MoVL Complexes ( $\mathrm{L}=\mathrm{N}-$, NH). Inorg. Chem 2017, 56, 6906-6919. [PubMed: 28571321]

73. Based on this finding, one would expect similar excitation energies for the $d_{x y}$ excited state $\left(d_{x}{ }^{2}-y^{2} \rightarrow d_{x y}\right.$ excitation) in both complexes.

74. Delle Chiaie KR; Biernesser AB; Ortuño MA; Dereli B; Iovan DA; Wilding MJT; Li B; Cramer $\mathrm{CJ}$; Byers JA The role of ligand redox non-innocence in ring-opening polymerization reactions catalysed by bis(imino)pyridine iron alkoxide complexes. Dalton Trans 2017, 46, 12971-12980. [PubMed: 28932853]

75. Stieber SCE; Milsmann C; Hoyt JM; Turner ZR; Finkelstein KD; Wieghardt K; DeBeer S; Chirik PJ Bis(imino)pyridine Iron Dinitrogen Compounds Revisited: Differences in Electronic Structure Between Four- and Five-Coordinate Derivatives. Inorg. Chem 2012, 51, 3770-3785. [PubMed: 22394054]

76. Hoffman BM; Lukoyanov D; Yang Z-Y; Dean DR; Seefeldt LC Mechanism of Nitrogen Fixation by Nitrogenase: The Next Stage. Chem. Rev 2014, 114, 4041-4062. [PubMed: 24467365]

77. Van Stappen C; Decamps L; Cutsail GE; Bjornsson R; Henthorn JT; Birrell JA; DeBeer S The Spectroscopy of Nitrogenases. Chem. Rev 2020.

78. Can M; Armstrong FA; Ragsdale SW Structure, Function, and Mechanism of the Nickel Metalloenzymes, CO Dehydrogenase, and Acetyl-CoA Synthase. Chem. Rev 2014, 114, 41494174. [PubMed: 24521136]

79. Holm RH; Lo W Structural Conversions of Synthetic and Protein-Bound Iron-Sulfur Clusters. Chem. Rev 2016, 116, 13685-13713. [PubMed: 27933770] 




Figure 1.

Experimental NRVS VDOS data of the ls- $\{\mathrm{FeNO}\}^{8}$ complex $[\mathrm{Fe}(\mathrm{TPB})(\mathrm{NO})]\left(\mathrm{BAr}^{\mathrm{F}}{ }_{4}\right)$ purple), the ls- $\{\mathrm{FeNO}\}^{9}$ complex $[\mathrm{Fe}(\mathrm{TPB})(\mathrm{NO})]$ (brown) and the ls- $\{\mathrm{FeNO}\}^{10}$ complex $\left[\mathrm{Na}(12 \text {-crown-4) })_{2}\right][\mathrm{Fe}(\mathrm{TPB})(\mathrm{NO})]$ (red) vs QCC-NCA fits (black). 


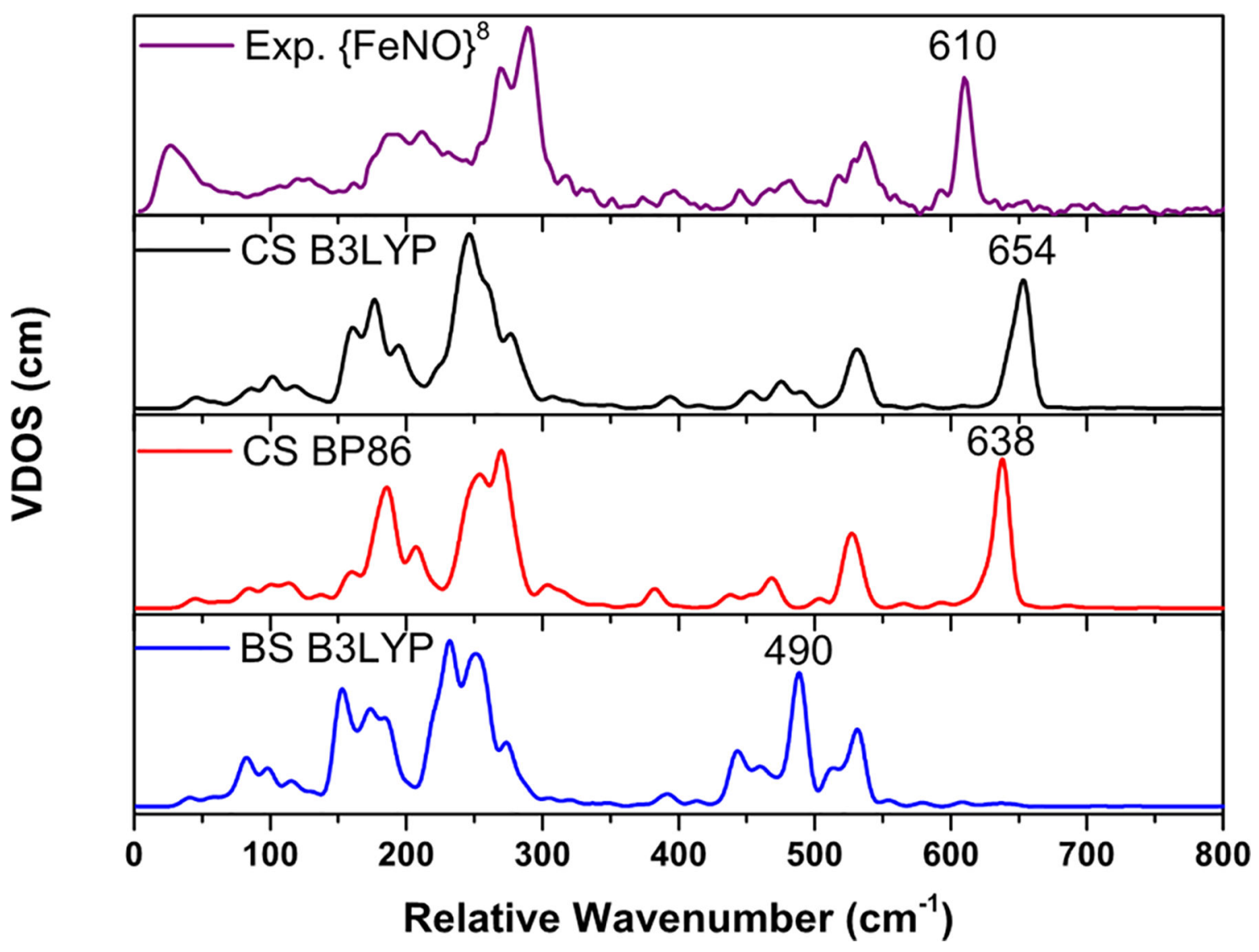

Figure 2.

Experimental NRVS VDOS data of the $1 \mathrm{~s}-\{\mathrm{FeNO}\}^{8}$ complex (top) in comparison with the spectra generated by closed-shell (middle) and broken-symmetry (bottom) calculations, using the indicated functionals together with the TZVP basis set. 
Dong et al.

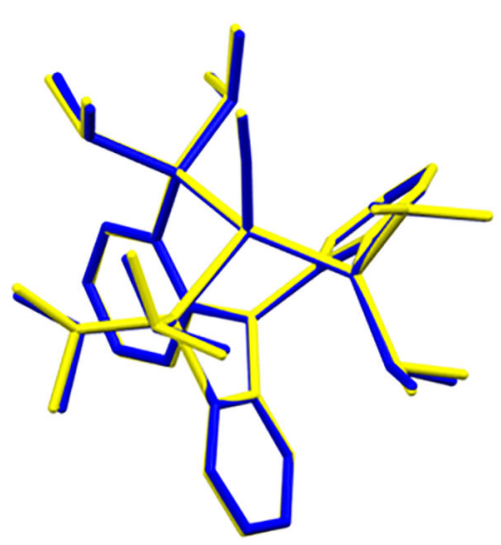

Is- $\{\mathrm{FeNO}\}^{8}$

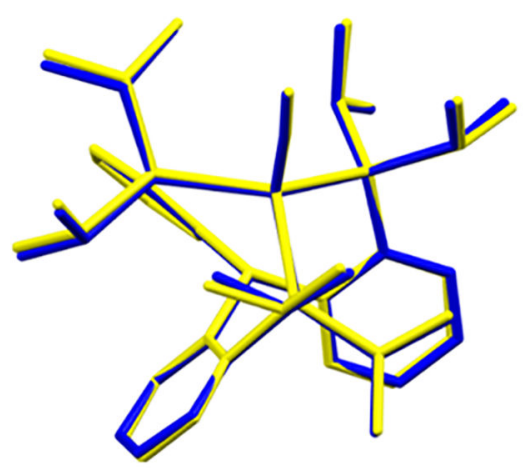

Is-\{FeNO $\}^{9}$
Page 26

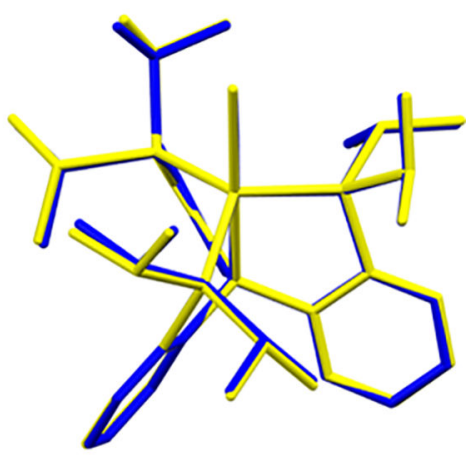

Is-\{FeNO $\}^{10}$

Figure 3.

Overlay of crystal structures (blue) and the BP86/TZVP-optimized structures (yellow) of the ls- $\{\mathrm{FeNO}\}^{8-10}$ series, $[\mathrm{Fe}(\mathrm{TPB})(\mathrm{NO})]^{+/ 0 /-}$, showing excellent agreement between the DFTpredictions and the experimental structures. 

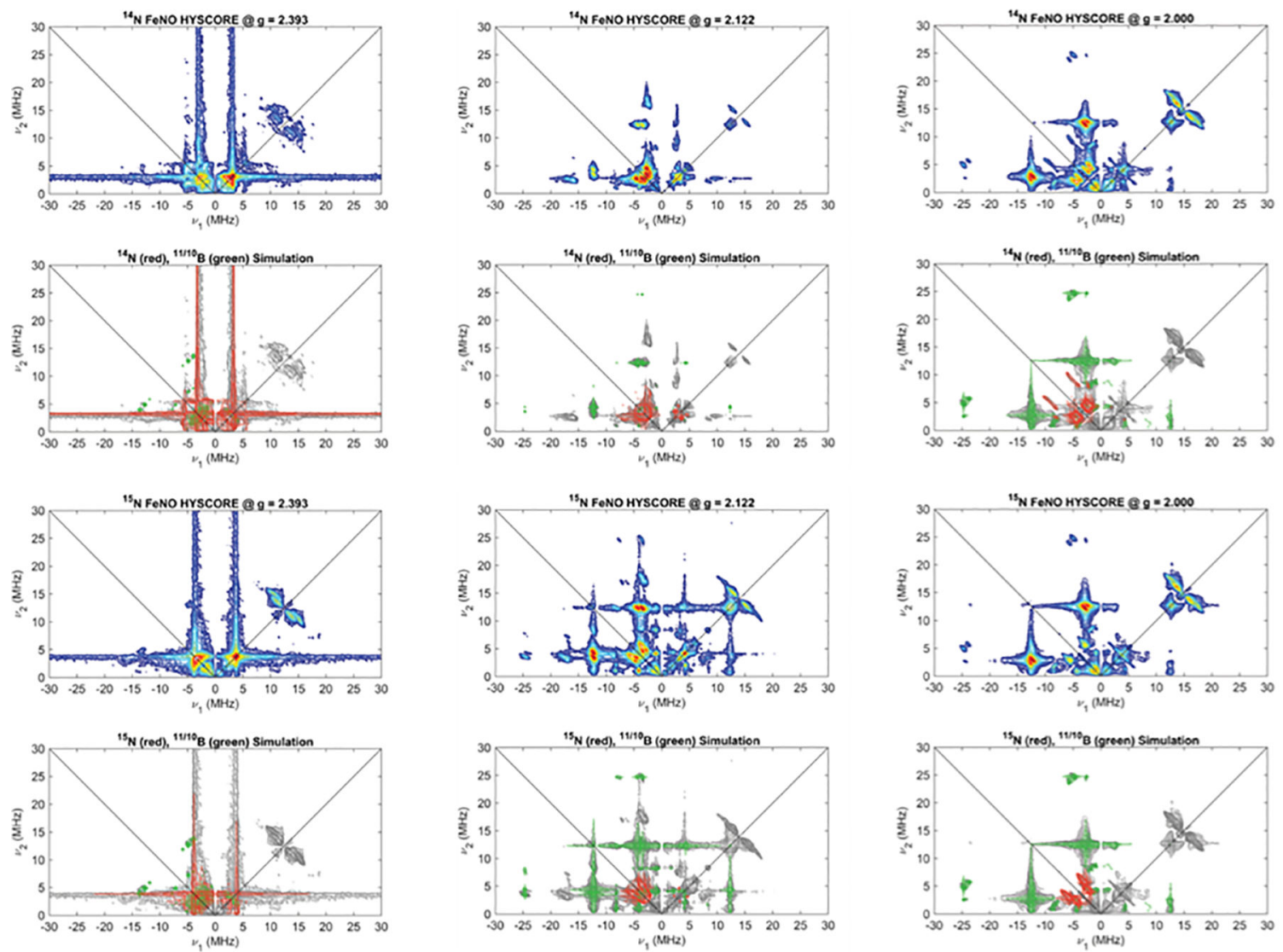

Figure 4.

Field-dependent X-band HYSCORE spectra of the ls- $\{\mathrm{FeNO}\}^{9}$ complex $[\mathrm{Fe}(\mathrm{TPB})$ $\left.\left({ }^{14 / 15} \mathrm{NO}\right)\right]$. The experimental data are plotted in color in the top panels, ranging from dark blue to red in increasing intensity. These same data are plotted in grey in the bottom panels, with ${ }^{14 / 15} \mathrm{~N}$ and ${ }^{11} \mathrm{~B}$ simulations overlaid in red and green, respectively. Unsimulated features centered around $15 \mathrm{MHz}$ in the $(+,+)$ quadrant arise from weakly coupled ${ }^{1} \mathrm{H}$ nuclei of the ligand or from solvent. Acquisition parameters: Temperature $=7 \mathrm{~K}$; microwave frequency $=9.711 \mathrm{GHz} ; \mathrm{B}_{0}=290 \mathrm{mT}(g=2.393), 327 \mathrm{mT}(g=2.122), 347 \mathrm{mT}(g=2.000)$; MW pulse length $(\pi / 2, \pi)=8 \mathrm{~ns}, 16 \mathrm{~ns} ; \tau=142 \mathrm{~ns}(g=2.393), 144 \mathrm{~ns}(g=2.122), 136 \mathrm{~ns}$ $(g=2.000) ; \mathrm{t}_{1}=\mathrm{t}_{2}=100 \mathrm{~ns} ; \Delta \mathrm{t}_{1}=\Delta \mathrm{t}_{2}=16 \mathrm{~ns} ;$ shot repetition time $(\mathrm{srt})=1 \mathrm{~ms}$. 


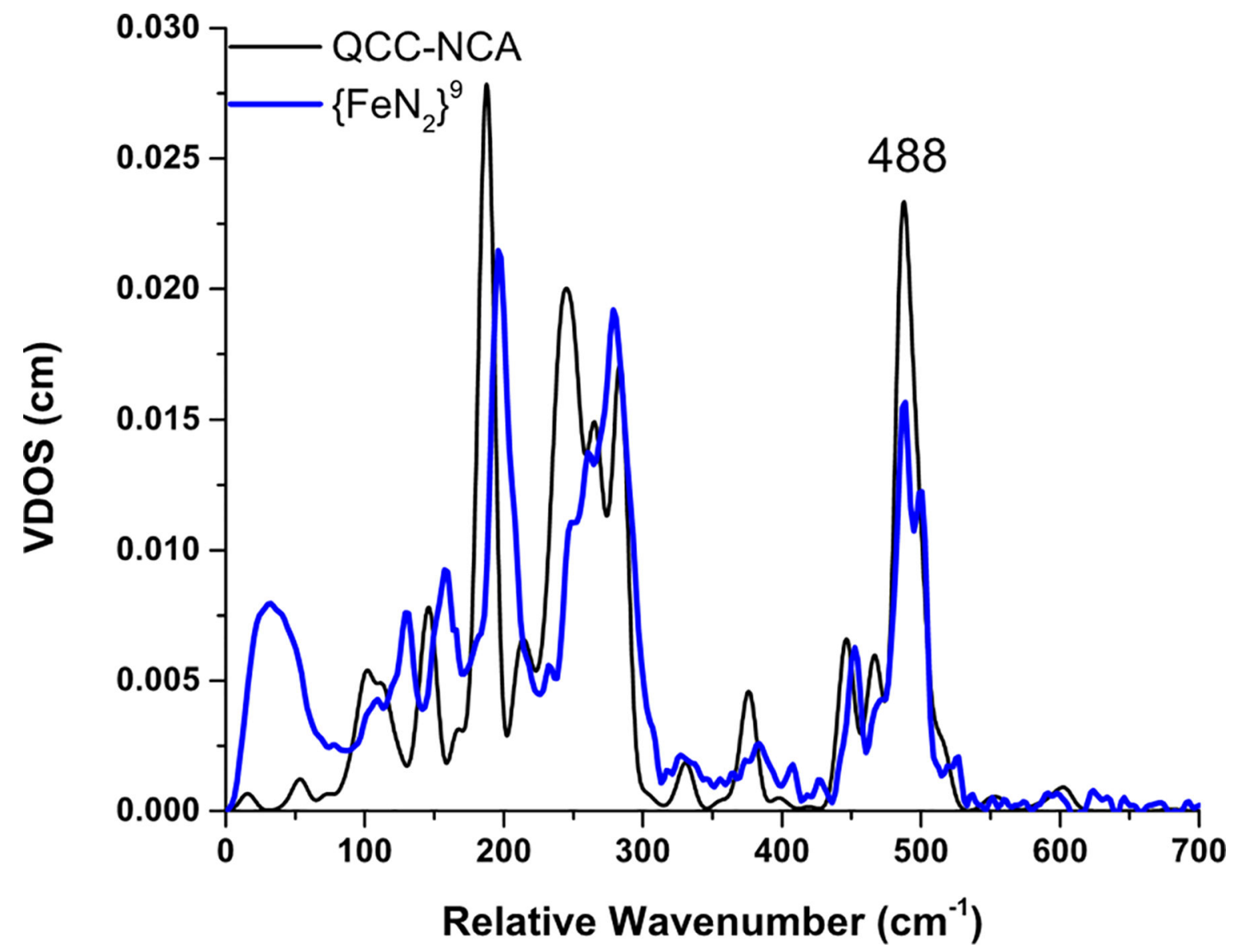

Figure 5.

Experimental NRVS VDOS data of the $\left\{\mathrm{FeN}_{2}\right\}^{9}$ complex $\left[\mathrm{Na}(12 \text {-crown-4) })_{2}\right]\left[\mathrm{Fe}(\mathrm{TPB})\left(\mathrm{N}_{2}\right)\right]$ (blue) vs a QCC-NCA fit (black). 


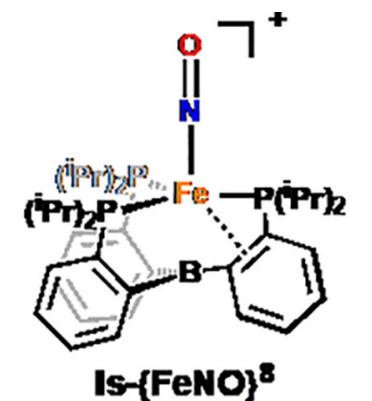

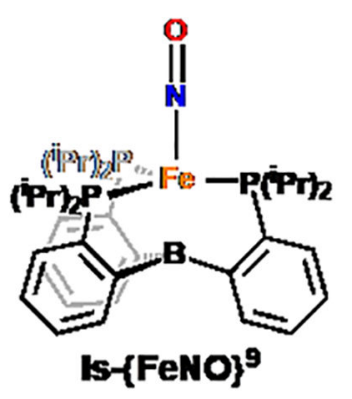

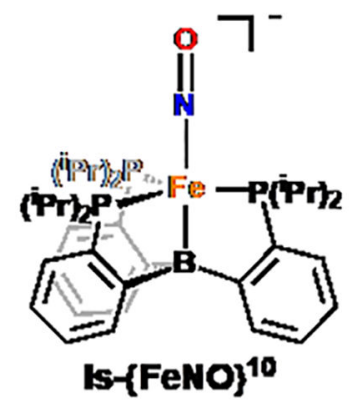

$v(\mathrm{~N}-\mathrm{O})=1745$

V(FeNO) $=610$

$\Delta \mathrm{E}_{\mathrm{Q}}=1.50$

$\delta=0.24$

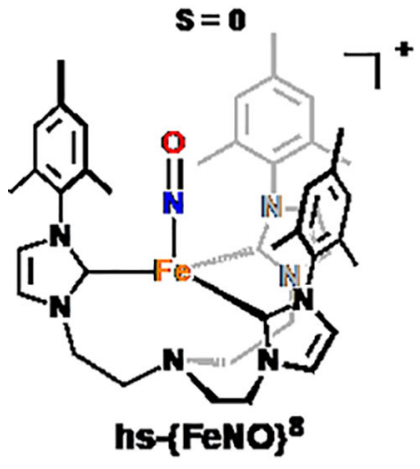

$v(N-O)=1667$

$\mathrm{V}(\mathrm{Fe}-\mathrm{NO})=583$

$\mathbf{v}(\mathrm{N}-\mathrm{O})=1568$

$\Delta \mathrm{E}_{\mathrm{Q}}=0.91$

$\delta=0.26$

$s=1 / 2$

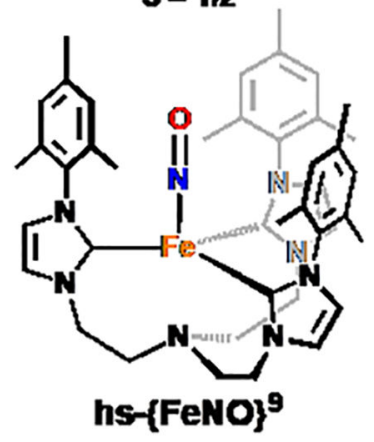

$\Delta E_{Q}=1.62$

$\delta=0.17$

$s=0$

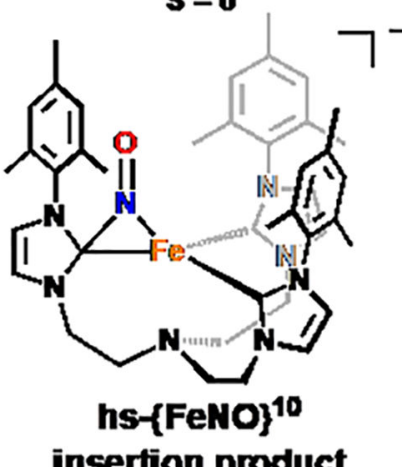

$v(N-O)=1686$

$v(\mathrm{Fe}-\mathrm{NO})=\mathrm{N} / \mathrm{A}$

$$
\begin{gathered}
\Delta E_{Q}=1.82 \\
\delta=0.37 \\
S=1
\end{gathered}
$$

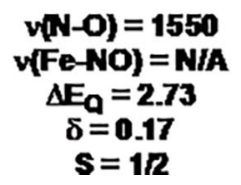

insertion product

$\mathrm{v}(\mathrm{N}-\mathrm{O})=1358$

v(Fe-NO) $=$ N/A

$\Delta E_{Q}=1.35$

$\delta=0.05$

$\mathbf{s}=\mathbf{0}$

Figure 6.

Comparison between the $[\mathrm{Fe}(\mathrm{TPB})(\mathrm{NO})]^{+/ 0 /-}$ and the $\left[\mathrm{Fe}\left(\mathrm{TIMEN}^{\mathrm{Mes}}\right)(\mathrm{NO})\right]^{+/ 0 /-}$ series. Stretching frequencies $v$ are in $\mathrm{cm}^{-1}, \Delta \mathrm{E}_{\mathrm{Q}}$ and $\delta$ are in $\mathrm{mm} / \mathrm{s}$. $\mathrm{S}$ is the total spin of the complex. 

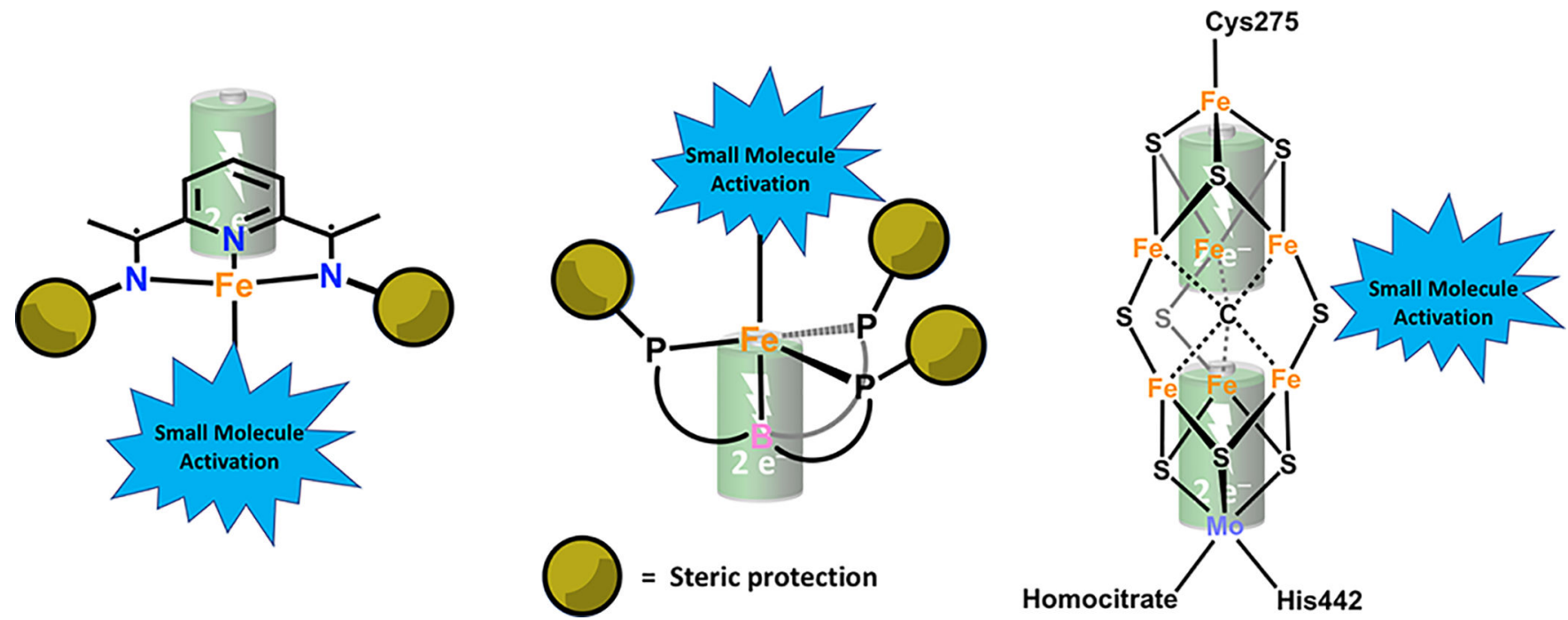

Figure 7.

Left: In typical non-innocent ligands, like the bis(imino)pyridine system, electrons can be stored in a ligand $\pi$ system. Middle: The TPB ligand used here is unusual, as it stores two electrons in a $\mathrm{Fe} \rightarrow \mathrm{B}$ dative bond. Right: In the active site of the enzyme nitrogenase, ironsulfur cluster are used for electron storage. In all cases, the electrons stored in this way can then be utilized for small-molecule activation. 

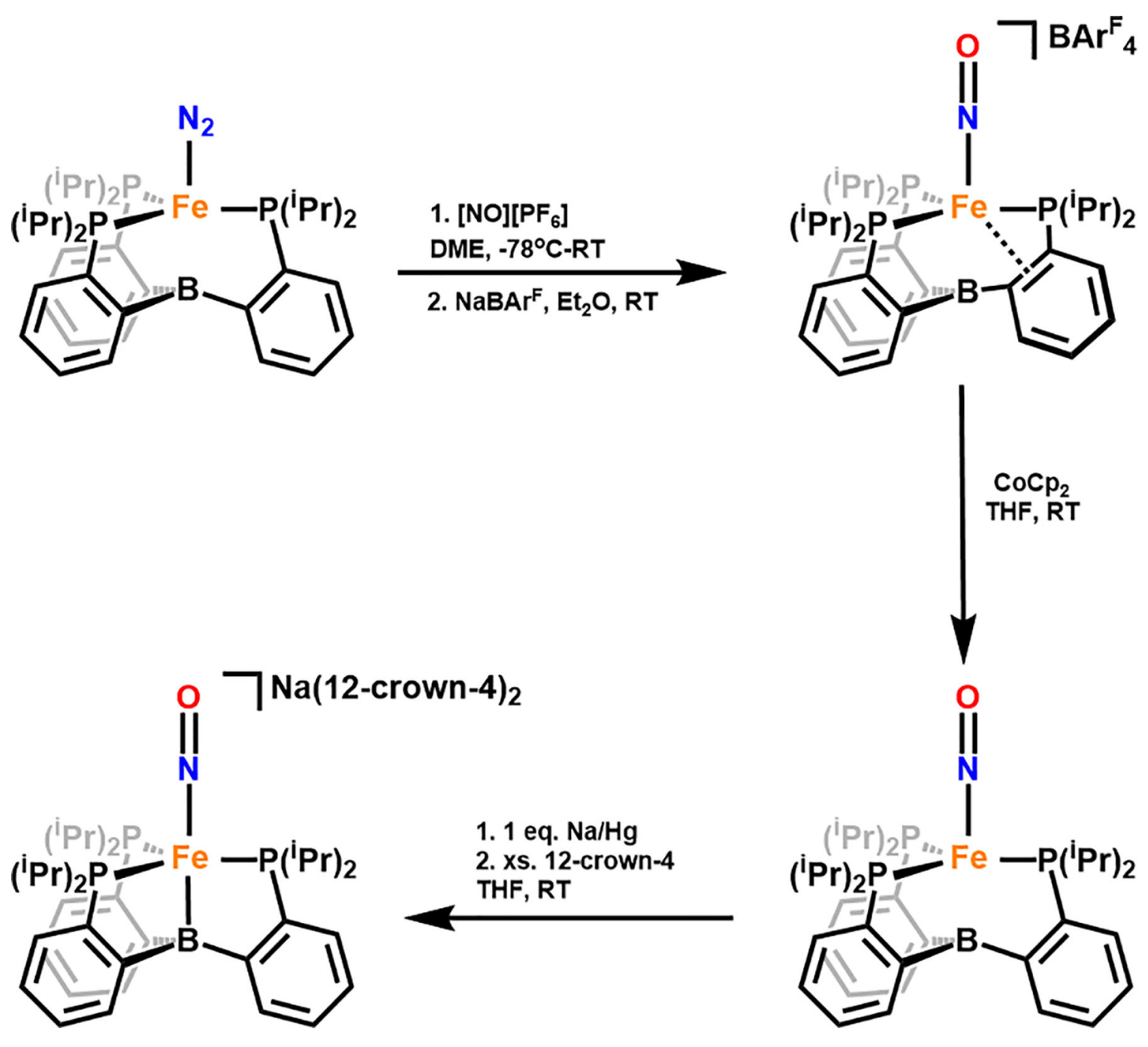

Scheme 1.

Reaction scheme for the $[\mathrm{Fe}(\mathrm{TPB})(\mathrm{XY})]$ complexes. 


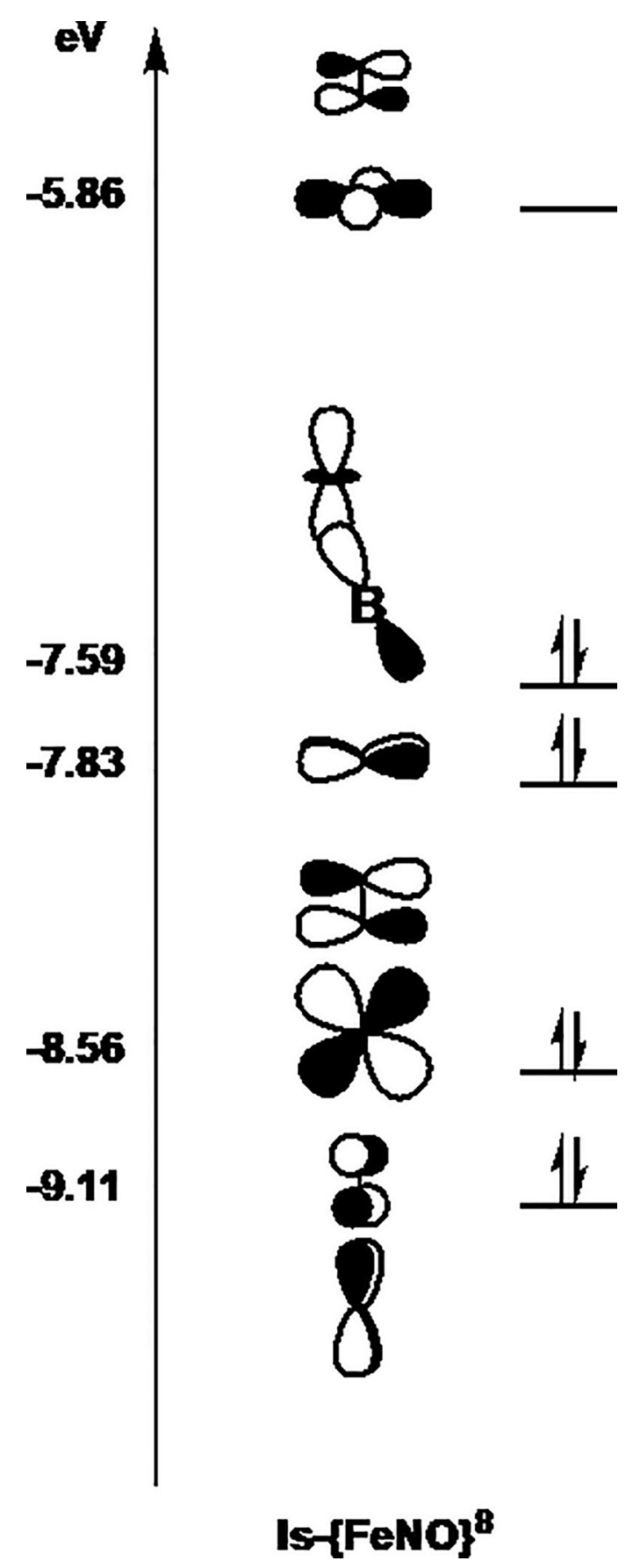

Scheme 2.

Schematic MO diagram of the $1 \mathrm{~s}-\{\mathrm{FeNO}\}^{8}$ complex, calculated with BP86/TZVP. 


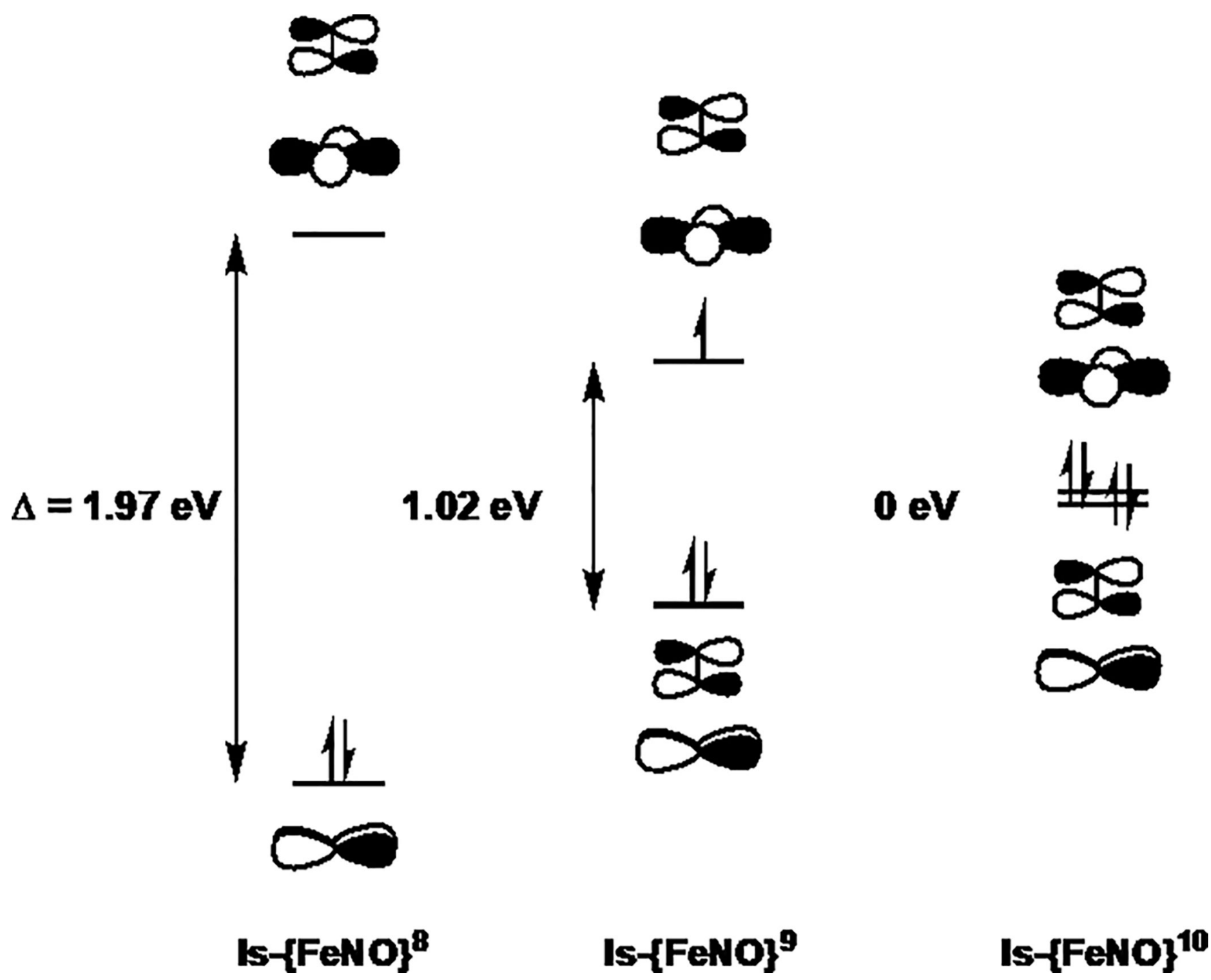

Scheme 3.

Ligand field splitting between the $\mathrm{d}_{\mathrm{x}}{ }^{2}-\mathrm{y}^{2}$ and the $\mathrm{d}_{\mathrm{xy}}$ orbitals, as a function of the $\mathrm{FeP}_{3}$ geometry in the $x y$-plane. 

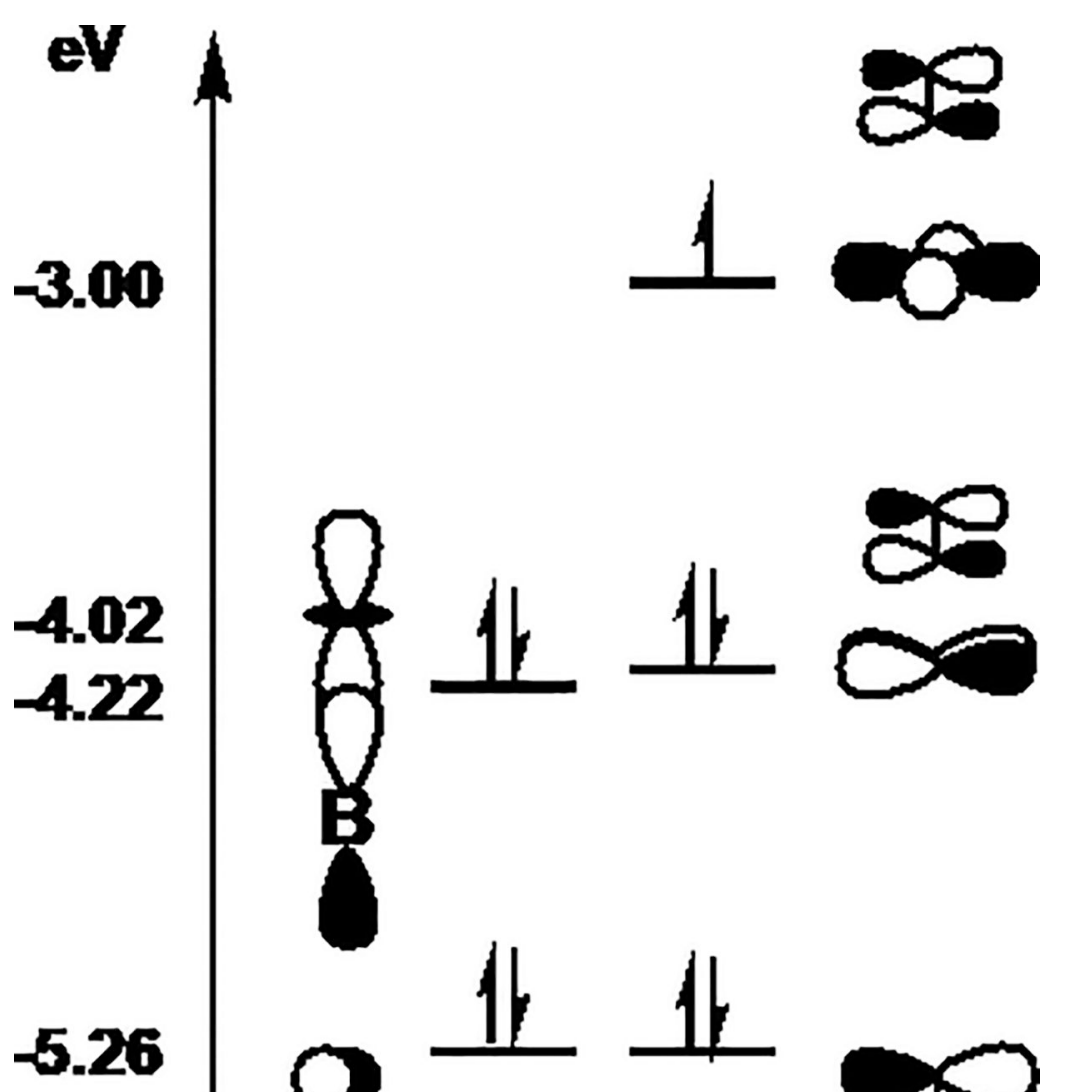

\section{Is $\{\text { FeNO }\}^{9}$}

Scheme 4.

Schematic MO diagram of the $1 s-\{\mathrm{FeNO}\}^{9}$ complex, calculated with BP86/TZVP. 

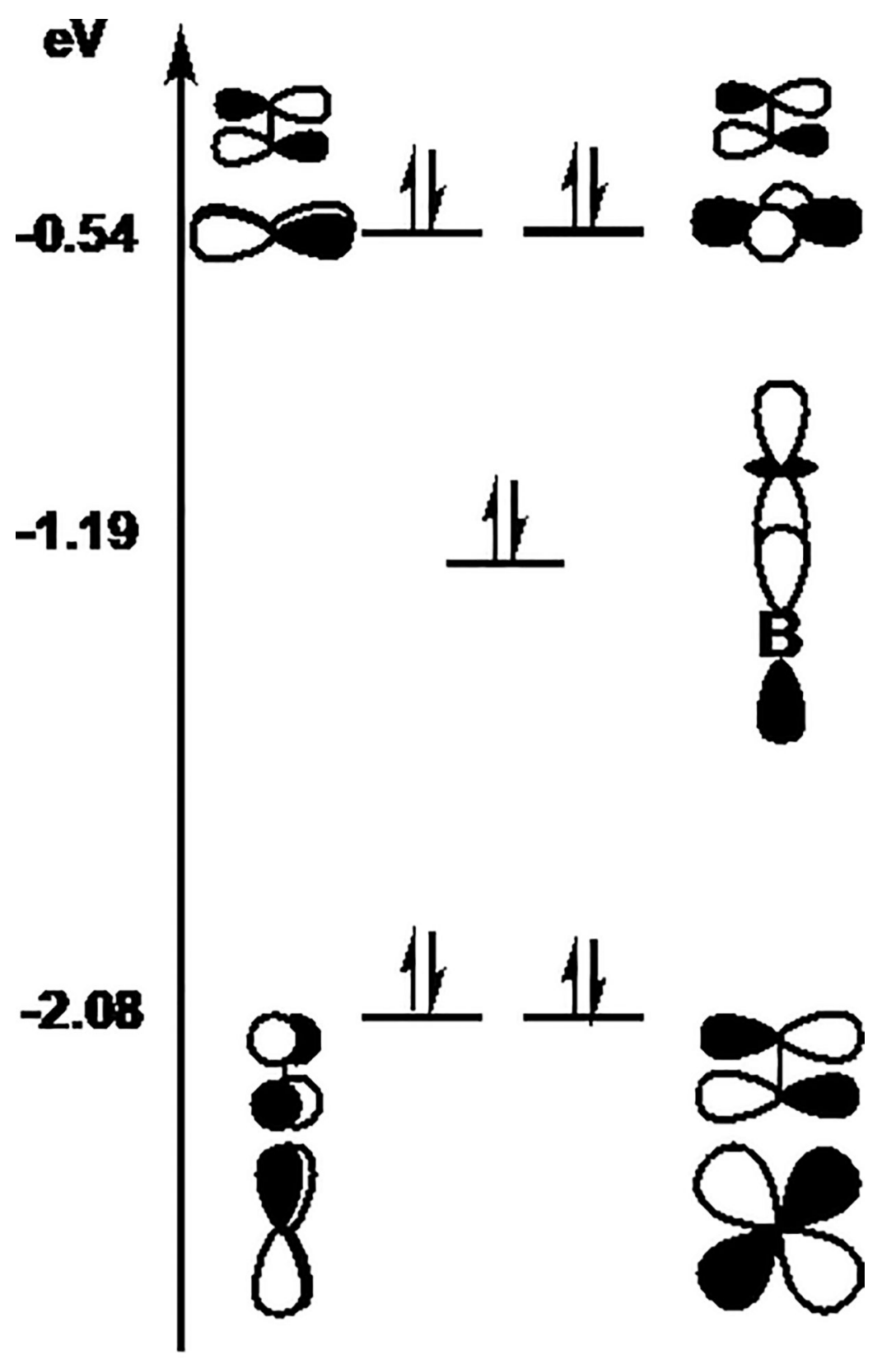

\section{Is $\{\text { FeNO }\}^{10}$}

\section{Scheme 5.}

Schematic MO diagram of the $1 \mathrm{~s}-\{\mathrm{FeNO}\}{ }^{10}$ complex, calculated with BP86/TZVP. 
Table 1.

Experimental structural and spectroscopic data versus computational results for the series of $1 \mathrm{~s}-\{\mathrm{FeNO}\}^{8-10}$ complexes.

\begin{tabular}{|c|c|c|c|c|c|c|}
\hline & \multicolumn{2}{|c|}{ ls- $\{\mathrm{FeNO}\}^{8}$} & \multicolumn{2}{|c|}{ Is-tFeNO $\}^{9}$} & \multicolumn{2}{|c|}{ Is- $\{\text { FeNO }\}^{10}$} \\
\hline & Exp. & BP86 & Exp. & BP86 & Exp. & BP86 \\
\hline & \multicolumn{6}{|c|}{ Geometric Parameters (§̊ and degrees) } \\
\hline $\mathbf{d}(\mathbf{N}-\mathbf{O})$ & 1.16 & 1.18 & 1.19 & 1.19 & 1.22 & 1.21 \\
\hline d(Fe-NO) & 1.66 & 1.66 & 1.67 & 1.66 & 1.65 & 1.65 \\
\hline d(Fe-B) & 2.31 & 2.32 & 2.45 & 2.42 & 2.45 & 2.46 \\
\hline$<\mathrm{Fe}-\mathrm{N}-\mathrm{O}$ & 176 & 174 & 176 & 176 & 179 & 180 \\
\hline d(Fe-P) & 2.28 & 2.33 & 2.28 & 2.30 & 2.21 & 2.24 \\
\hline d(Fe-P) & 2.28 & 2.33 & 2.30 & 2.32 & 2.21 & 2.24 \\
\hline d(Fe-P) & 2.29 & 2.31 & 2.35 & 2.37 & 2.23 & 2.24 \\
\hline P-Fe-P & 100 & 99 & 106 & 107 & 115 & 116 \\
\hline P-Fe-P & 101 & 101 & 111 & 110 & 116 & 116 \\
\hline \multirow[t]{2}{*}{ P-Fe-P } & 154 & 154 & 126 & 126 & 116 & 116 \\
\hline & \multicolumn{6}{|c|}{ Spectroscopic Parameters: Vibrational $\left(\mathrm{cm}^{-1}, \mathrm{mdyn} / \AA ̊\right.$ and $\left.\mathrm{mdyn} \bullet \AA ̊ 丿\right)$} \\
\hline $\mathbf{n}(\mathbf{F e}-\mathrm{NO})$ & 610 & 638 & 583 & 621 & 602 & 633 \\
\hline $\mathbf{n}(\mathbf{N}-\mathbf{O})$ & 1745 & 1751 & 1667 & 1692 & 1568 & 1607 \\
\hline $\mathbf{d}_{\mathrm{lb}}(\mathrm{Fe}-\mathrm{N}-\mathrm{O})$ & $540 / 537$ & $531 / 525$ & $522 / 506$ & $516 / 508$ & $543 / 525$ & $561 / 535$ \\
\hline f(Fe-NO) & 4.53 & 4.95 & 4.15 & 4.80 & 4.45 & 5.07 \\
\hline $\mathbf{f}(\mathbf{N}-\mathbf{O})$ & 12.5 & 12.4 & 11.3 & 11.5 & 9.79 & 10.1 \\
\hline \multirow[t]{2}{*}{$\mathbf{f}(\mathrm{Fe}-\mathrm{B})$} & 0.51 & 0.51 & 0.42 & 0.42 & 1.56 & 1.56 \\
\hline & \multicolumn{6}{|c|}{ Spectroscopic Parameters: Mössbauer (mm/s) } \\
\hline d & 0.24 & 0.30 & 0.26 & 0.25 & 0.17 & 0.20 \\
\hline \multirow[t]{2}{*}{$\mathbf{D E}^{\mathbf{Q}}$} & 1.50 & 1.43 & 0.91 & 0.81 & 1.62 & 1.53 \\
\hline & \multicolumn{6}{|c|}{ Spectroscopic Parameters: Pulse EPR (MHz) } \\
\hline$A\left({ }^{14} \mathbf{N}\right)$ & - & - & $-6.0,-8.3,3.8$ & $-0.8,-5.1,8.8$ & - & - \\
\hline $\mathbf{A}\left({ }^{11} \mathbf{B}\right)$ & - & - & $14.7,14.7,18.0$ & $-15.2,-15.6,-20.3$ & - & - \\
\hline
\end{tabular}


Table 2.

Experimental NRVS data vs. QCC-NCA simulation results $\left(\mathrm{in}^{-1}\right.$ ) and vibrational assignments for the ls$\{\mathrm{FeNO}\}^{8-10}$ series.

\begin{tabular}{|c|c|c|c|c|c|c|}
\hline & \multicolumn{2}{|c|}{ ls- $\{\mathrm{FeNO}\}^{8}$} & \multicolumn{2}{|c|}{ Is- $\{\mathrm{FeNO}\}^{9}$} & \multicolumn{2}{|c|}{ Is- $\{\mathrm{FeNO}\}^{10}$} \\
\hline & Exp. & QCC-NCA & Exp. & QCC-NCA & Exp. & QCC-NCA \\
\hline $\mathbf{n}\{\mathrm{Fe}-\mathrm{N})$ & 610 & 610 & 583 & 583 & 602 & 602 \\
\hline $\mathrm{n}(\mathrm{N}-\mathrm{O})$ & 1745 & 1745 & 1667 & 1667 & 1568 & 1568 \\
\hline $\mathrm{d}\{\mathrm{Fe}-\mathrm{N}-\mathrm{O})$ & 537 & 535 & $506(500)$ & $506(504)$ & 525 & 536 \\
\hline d(Fe-N-O) & 540 & 544 & 522 & 527 & 543 & 570 \\
\hline
\end{tabular}


Table 3.

Summary of key force constants.

\begin{tabular}{|c|c|c|c|c|c|}
\hline Force Constant & Is- $\{\mathrm{FeNO}\}^{8}$ & Is- $\{\mathrm{FeNO}\}^{9}$ & Is- $\{\mathrm{FeNO}\}^{10}$ & $\left\{\mathrm{FeN}_{2}\right\}^{9}$ & Force Constant \\
\hline $\mathrm{Fe}-\mathrm{NO}$ & 4.53 & 4.15 & 4.45 & 2.62 & $\mathrm{Fe}-\mathrm{N}_{2}$ \\
\hline $\mathrm{Fe}-\mathrm{B}$ & 0.51 & 0.42 & 1.56 & 1.21 & $\mathrm{Fe}-\mathrm{B}$ \\
\hline $\mathrm{N}-\mathrm{O}$ & 12.5 & 11.3 & 9.79 & 14.9 & $\mathrm{~N}-\mathrm{N}$ \\
\hline $\mathrm{Fe}-\mathbf{P}_{4} / \mathbf{P}_{5} / \mathbf{P}_{6}$ & $1.40 / 1.56 / 1.91$ & $1.03 / 1.17 / 0.98$ & $1.96 / 1.99 / 1.93$ & $3.06 / 1.36 / 1.32$ & $\mathrm{Fe}-\mathrm{P}_{4} / \mathrm{P}_{5} / \mathrm{P}_{6}$ \\
\hline $\mathrm{Fe}-\mathrm{N}-\mathrm{O}_{\mathrm{lb}}$ & 0.41 & 0.46 & 0.54 & 0.51 & $\mathrm{Fe}-\mathrm{N}-\mathrm{N}_{\mathrm{lb}}$ \\
\hline $\mathrm{Fe}-\mathrm{N}-\mathrm{O}_{\mathrm{lb}}$ & 0.57 & 0.43 & 0.54 & 0.62 & $\mathrm{Fe}-\mathrm{N}-\mathrm{N}_{\mathrm{lb}}$ \\
\hline
\end{tabular}

